\title{
Toward a Model of Transfer as Sense-Making
}

\author{
Timothy J. Nokes-Malach \\ Department of Psychology \\ Learning Research and Development Center \\ University of Pittsburgh \\ Jose P. Mestre \\ Departments of Physics and Educational Psychology \\ Beckman Institute for Advanced Science and Technology \\ University of Illinois
}

\begin{abstract}
We propose a novel theoretical framework for knowledge transfer that consists of constructing a representation of context, generating a solution, and evaluating whether the solution makes sense given that context. Sense-making and satisficing processes determine when the transfer cycle begins and ends, and the classical mechanisms of transfer (identical rules, analogy, knowledge compilation, and constraint violation) are triggered under different representations of context. We use this framework to interpret student transfer behaviors with examples from the literature in the domains of physics and mathematics. We view this framework as a research tool to explore the dynamic nature and complexity of transfer by highlighting critical features and issues that a complete model of transfer must address. We describe how the framework relates to the classical and recent alternative approaches to understanding transfer and discuss the implications for theory development and instruction.
\end{abstract}

One of the most important functions of the human mind is the ability to use prior knowledge and experience to solve novel problems, an ability that is likely to have contributed to our survival as a species (at least thus far). The learning and cognitive sciences have referred to this as the ability to transfer knowledge or skills from one problem or task to another. Transfer appears to be a natural aspect of our cognition. It is evident in our day-to-day lives, from reading and responding to a new e-mail, to learning to use a new version of a computer application or mobile technology, to preparing a class lesson on a new topic. Without the ability to transfer what we know to new situations, we would be unable to perform the most basic of cognitive tasks such as reading and comprehending this text, much less attain the array of artistic, technological, and scientific achievements our species has accomplished to date. Although our everyday experience tells us transfer is a ubiquitous aspect of human cognition, a paradox arises when we consider the empirical literature on the subject.

Correspondence should be addressed to Timothy J. Nokes-Malach, Learning Research and Development Center, University of Pittsburgh, 3939 O’Hara Street, Pittsburgh, PA 15260. E-mail: nokes@pitt.edu
Psychologists have been investigating transfer for more than 100 years. During this time researchers have made progress in describing different types of transfer including: near transfer between similarly structured problems and contexts; far transfer between problems that differ significantly on at least one dimension of knowledge domain, physical context, temporal context, and so on (see Barnett \& Ceci, 2002 , for a classification of nine dimensions of far transfer); procedural transfer of cognitive skills for "knowing how" to solve a problem; and declarative transfer of "knowing that" such as facts, strategies, or principles that can be used for problem solving, among others (see Schunk, 2004, for an overview of 12 types of transfer). Research has also made much progress in understanding some of the basic cognitive processes involved in transfer, such as the role of analogical reasoning (Gentner, Holyoak, \& Kokinov, 2001) or how we interpret declarative concepts to solve new problems (Singley \& Anderson, 1989). Despite this progress, transfer has also proven to be an elusive phenomenon, often evading the scientist's observation and manipulation in the laboratory. As many review articles are quick to point out, the literature is replete with examples of so-called transfer failures in which transfer did not occur as the researchers expected (see 
Bransford \& Schwartz, 1999; Day \& Goldstone, 2012; and Detterman \& Sternberg, 1993, for reviews).

So if everyday transfer can be so easy, fluid, and fundamentally a part of human activity, then why do we have so many apparent failures of finding and demonstrating this ability in the psychologist's laboratory? In this article we aim to address this paradox by synthesizing and integrating several lines of research into a general framework for interpreting and analyzing transfer. We constrain our examination of transfer to novice problem solvers because we are particularly interested in how students learn and transfer their knowledge in the domains of math and science. Our goal is to articulate a framework that can be used as a research tool to shed light upon the features and issues that a successful model of transfer must address. We hypothesize a set of general cognitive processes - a transfer cycle - that is activated in both situations of transfer successes and failures. Which outcome occurs depends upon the frame that is generated, the knowledge components (KCs) activated and their use in the construction of context, and the cognitive mechanisms triggered to adapt and apply that knowledge.

We view transfer as a dynamic process in which the learner engages in the highly selective activation and application of knowledge to create a representation that allows her or him to make sense of the situation in order to accomplish some goal or perform some task. Our framework consists of a collection of transfer processes including sense-making, satisficing, and four basic mechanisms (identical rules, analogy, knowledge compilation, and constraint violation). The sensemaking processes drive the transfer cycle and specify when transfer begins and ends. We define sense-making as the act of determining whether the task goals have been accomplished to the satisfaction of the solver based on coordination of prior knowledge with information from the environment and the framing of the task. This set of processes (to be spelled out in detail in the description of the framework section) operates in accordance with Simon's notion of satisficing (Simon, 1956, 1993, 1996) and drives the application of four basic mechanisms of transfer. Within this framework we focus on the roles played by learner goals, prior knowledge, social and motivational factors, the environment, and task framing in the transfer process.

Next we describe the classical approach to understanding transfer and review four cognitive mechanisms proposed in the literature. We then summarize the primary criticisms of this approach and briefly review two more recent views of transfer as situated (D. W. Carraher \& Schliemann, 2002; Greeno \& the Middle-School Mathematics through Applications Project Group [MMAP], 1998; Lave \& Wegner, 1991 ) and as preparation for future learning (Bransford \& Schwartz, 1999; Schwartz, Bransford, \& Sears, 2005). With this theoretical backdrop, we then present our framework for analyzing transfer that builds on and extends the classical view to address some of the criticisms raised by the alternative approaches.

\section{CLASSIC TRANSFER MECHANISMS}

The classical approach is typically described as the transportation of knowledge elements or components (KCs) that are learned from one situation or task and applied to another (Bransford \& Schwartz, 1999; D. W. Carraher \& Schliemann, 2002; Day \& Goldstone, 2012; Gick \& Holyoak, 1987). We review four mechanisms that use this approach to account for some critical aspects of transfer. We call them transfer mechanisms because they each use a different set of information processes and representations to transfer prior knowledge. This definition is consistent with philosophy of science perspectives that define four key aspects of mechanism, including phenomenal aspect - the mechanism does something, componential aspect - the mechanism consists of subparts, casual aspect - there are causal relationships between the parts, and organizational aspect - causal relations are organized spatially and temporally (Bechtel, 2008; Craver \& Bechtel, 2006). In addition to conforming to the philosophical definition, these particular mechanisms have been instantiated as computational models and have received significant empirical evidence for their existence.

\section{Identical Rules}

Edward L. Thorndike was one of the first psychologists to articulate the transfer problem and to develop a systematic program of research to investigate it. Based on his empirical investigations, he proposed the theory of identical elements (Thorndike \& Woodworth, 1901), where transfer occurs to the degree that the elements between two problems or tasks overlap. Thorndike originally operationalized the elements of transfer as the stimulus components of the task, which was consistent with the stimulus-response theories of the time. For example, the amount of transfer expected for estimating the area of differently shaped figures (e.g., triangles, rectangles, etc.) was determined by the amount of stimulus overlap between training and test items (Thorndike \& Woodworth, 1901). The more overlap, the more transfer expected.

Singley and Anderson (1989) have since reformulated the identical elements theory using a modern informationprocessing approach whereby the elements are now defined as procedural knowledge representations called "production rules" within the ACT-R cognitive architecture. Production rules represent an individual's procedural knowledge for knowing how to perform tasks, solve problems, and more generally act in the world. It is knowledge for doing and is separate from declarative knowledge, which has different representational characteristics and properties. Each rule consists of a set of conditions and actions that are formalized as IF-THEN statements. For example, a procedural rule for solving the subtraction problem $4-3=$ ? might be formalized as "IF I am solving a subtraction problem and attending to $4-3$, THEN write 1." Production rules can include both 
constants and variables in the representation. Rules that include variables can apply to different contexts in which those variables generalize. However, production rules are also goal specific and apply only to situations that use the knowledge in the same way (i.e., have the same goals); this constraint has been called the use-specificity principle (Singley \& Anderson, 1989).

Transfer is determined by the number of overlapping production rules between two tasks. An advantage of this approach is that one can generate precise predictions for the amount of transfer expected by conducting a cognitive task analysis. A cognitive task analysis involves using multiple streams of behavioral data (e.g., verbal protocols and reaction times) to generate hypotheses about the underlying content and number of production rules required to perform a task (Card, Moran, \& Newell, 1983; Kieras \& Polson, 1985). This approach has been successful in predicting transfer in a number of procedural skill-based domains including learning to use a device (Kieras \& Bovair, 1986), computer programming (Anderson, Conrad, \& Corbett, 1989), and text editing (Bovair, Kieras, \& Polson, 1990; Singley \& Anderson, 1989).

Although this mechanism can account for transfer across an array of skill-based tasks, it cannot account for declarative transfer ${ }^{1}$ or transfer to tasks that use the same knowledge but in a different way, that is, for different goals (Pennington, Nicolich, \& Rahm, 1995; Singley \& Anderson, 1989). For example, Pennington et al. (1995) found positive transfer across two computer subskills of evaluating versus generating LISP programming code. The amount of transfer observed was more than that predicted by a production rule task analysis because the goals required for the two tasks were different (i.e., evaluating vs. generating). The authors interpreted this result as support for declarative transfer across the two tasks. Although the production rule approach alone could not account for this result, several other cognitive mechanisms have been proposed to account for declarative transfer including analogy, knowledge compilation, and constraint violation.

\section{Analogy}

Analogy is another classical mechanism of knowledge transfer (Gentner, 1983; Gentner et al., 2001; Gick \& Holyoak, 1980, 1983). It operates through the following three general processes: (a) retrieving a prior exemplar, (b) creating an alignment and mapping between the exemplar and the representation of the current problem, and (c) drawing an inference appropriate to the current problem. Analogies can transfer either declarative or procedural aspects of knowledge (Chen, 2002; Salvucci \& Anderson, 1994). Much prior work has shown that students can transfer declarative knowledge

\footnotetext{
${ }^{1}$ In the knowledge compilation section, we describe the complementary computational mechanism in Anderson's ACT-R cognitive architecture that can account for declarative-to-procedural transfer (Anderson \& Lebiere, 1998).
}

from a prior example and then use that knowledge to solve a new problem (e.g., Bassok, 1990; Gick \& Holyoak, 1980; Ross, 1987). For example, in the classic analogy work using Duncker's radiation problem (Gick \& Holyoak, 1980), when students were given a hint to use the prior military general problem, they were able to successfully transfer the concept of the convergence solution to solve the radiation problem. Research has also shown that students are sensitive to procedural similarity between problems (Chen, 2002) and can transfer problem-solving procedures (Anderson, Finchman, \& Douglas, 1997; Nokes \& Ohlsson, 2005). Chen (2002) demonstrated that students were more efficient (faster and more accurate) in solving story puzzle problems when those problems shared a procedural solution in addition to a general concept and strategy.

There is a vast theoretical and empirical literature on analogical reasoning and problem solving, and much of this work has focused on identifying the factors that affect exemplar access and the cognitive processes involved in the retrieval, alignment, and mapping of an exemplar to the representation of the current problem (see Forbus, Gentner, \& Law, 1995; Hofstadter \& Mitchell, 1994; Holyoak \& Thagard, 1989; Hummel \& Holyoak, 1997; Keane, Ledgeway, \& Duff, 1994, for computational models of these processes). Much of this research has shown that novices typically make analogies to near transfer problems and are less likely to spontaneously make them to far transfer problems (see Reeves \& Weisberg, 1994, for a review). The primary explanation for this phenomenon is that the appropriate analogue is less likely to be successfully accessed and recalled when the surface features differ from the representation of the transfer task. That is, novices do not typically encode new problems by their deep conceptual or structural features and therefore, when recalling prior analogues for a new problem, they often rely on the surface features of the problem (Docktor, Mestre, \& Ross, 2012; Hardiman, Dufresne, \& Mestre, 1989; Ross, 1984, 1987).

This bias for relying on the problem surface features has led researchers to investigate learning processes that can lead to more abstract problem representations at encoding. Much work has shown that if a more abstract knowledge representation, often described as a schema, can be constructed at encoding, the probability of transfer increases (Gick \& Holyoak, 1983). A schema is a knowledge representation of a concept, problem, or situation that captures the prototypical elements of the problem (Gick \& Holyoak, 1983; Thorndyke, 1984). Research has shown that comparing two analogues at encoding leads to greater schema acquisition supporting later transfer (see Alfieri, Nokes-Malach, \& Schunn, 2013, for a meta-analytic review). Analogy theory and models also specify that abstraction can take place at the time of transfer through the re-represention of the source analogue, but much less research has examined this possibility.

In sum, research has shown that novices typically apply exemplar knowledge to near transfer problems that share 
surface features unless they are prompted to compare across problems at encoding to facilitate the acquisition of a more abstract representation. In our framework we focus on how novices typically use analogies to solve new problems in math and science domains in the absence of such instructional assistance.

\section{Knowledge Compilation}

Knowledge compilation operates like a translation device, interpreting prior declarative knowledge into a set of procedures or cognitive rules to perform a specific task (Anderson, 1982, 1987). We view this as a transfer mechanism because it provides a process by which one can utilize prior knowledge acquired from one situation (e.g., a class lecture) to solve a new problem in another (e.g., statistics homework). The mechanism works by using a set of general interpretative (production) rules to retrieve and apply prior declarative knowledge in the form of facts, instructions, or principles to perform a given task. This interpretation process generates new production rules that embed the declarative knowledge into the procedural rules given a particular goal.

This mechanism has successfully accounted for many instances of declarative-to-procedural transfer from generating geometry proofs (Anderson, 1982; Anderson, Greeno, Kline, \& Neves, 1981), to performing aviation simulation tasks (Taatgen, 2002; Taatgen \& Lee, 2003), to learning the past tense of English words (Taatgen \& Anderson, 2002). Although this mechanism has a broad scope of transfer because it can apply declarative knowledge to an array of uses and situations, it also requires substantial cognitive processing to interpret and apply that knowledge to a given scenario (Anderson, 1987). This high level of cognitive processing can cause performance errors because of the working memory limitations that constrain how much declarative information can be retrieved. For example, many of the early errors in cognitive skill acquisition have been attributed to failures to recall declarative facts during practice (Anderson, 1987; Anderson \& Jeffries, 1985).

\section{Constraint Violation}

Constraint violation is similar to knowledge compilation in that it also provides a mechanism for declarative-toprocedural knowledge transfer, but it differs in the particular processes of transferring the declarative knowledge (Ohlsson, 1996; Ohlsson \& Rees, 1991b). It operates through a three-step cycle of generating, evaluating, and revising. The learner first generates a potential solution to a given problem using problem-solving rules or heuristics. She then evaluates the solution with prior declarative knowledge stated as a constraint. For example, a student might have learned the principle that for any multidigit subtraction problem with whole numbers $\mathrm{N}-\mathrm{M}=\mathrm{R}$, then $\mathrm{R} \leq \mathrm{N}$. If she generates a solution that violates this constraint, she would then revise those procedures and attempt a new solution. This process iterates until a viable solution is constructed for the given problem. This mechanism enables the transfer of prior conceptual knowledge to new situations to support problem solving and the discovery of new procedures. Unlike knowledge compilation that interprets declarative knowledge for only the initial creation of a procedural rule, the constraint violation mechanism uses declarative knowledge throughout the development and mastery of procedural knowledge (Ohlsson \& Rees, 1991b).

This mechanism can discover the correct problem-solving procedures without any prior examples illustrating such procedures or instructions describing them. It can construct these procedures by using abstract conceptual knowledge to evaluate and guide the revision of incorrect actions. However, this mechanism also requires much cognitive processing and will lead to many errors in the process of trying to create them. Unlike the other mechanisms, this mechanism embeds a satisficing component within it that involves determining whether the current solution or performance violates any prior knowledge constraints. Because the declarative knowledge constraints typically apply to many problems within a domain, this mechanism can have a broad scope of transfer. This mechanism has been able to model declarative-toprocedural transfer in arithmetic (Ohlsson, Ernst, \& Rees, 1992; Ohlsson \& Rees, 1991a, 1991b) and chemistry (Ohlsson, 1993). It has also been used as the theoretical basis for constraint-based instruction (Ohlsson, 1992; Ohlsson \& Mitrovic, 2006). Researchers have used the theory to design intelligent tutoring systems for teaching cognitive skills in domains such as computer programming, language learning, architectural design, and physics, among others (see Mitrovic, 2012, for a review).

\section{Summary and Critique}

The classical view operationalizes transfer as the application of prior knowledge (e.g., rules, examples, strategies, and constraints) to a new task or problem. Each classical mechanism has been successful in accounting for some aspects of transfer but not others. Rules can account for procedural transfer to very similar problems but not declarative transfer to problems with different goals. Analogy accounts well for novices' use of exemplars to solve near transfer problems, but for far transfer it requires the acquisition of more abstract knowledge structures (i.e., schemas) or additional cognitive processes such as re-representation. Knowledge compilation can account for declarative transfer of fact-based knowledge to new problems, but the process requires substantial processing to interpret that knowledge into problem-solving actions. Similarly, constraint violation can capture transfer of principle knowledge but requires iterative cycles of applying that knowledge to facilitate problem solving.

This general approach to transfer has also been widely debated and critiqued in the literature (e.g., D. W. Carraher 
\& Schliemann, 2002; Lave, 1988). We suspect that such criticism is motivated by the multiple failures to obtain transfer in laboratory settings (e.g., Bassok \& Holyoak, 1989; Reed, Dempster, \& Ettinger, 1985). We do not reiterate all of the critiques here but instead focus on four central criticisms described by Lobato (2006, 2012; for reviews see Day \& Goldstone, 2012; Greeno, 2006; Lave, 1988). First, the classical paradigm examines only a very narrow definition and methodology for assessing transfer that focuses on the direct application of prior knowledge in problem-solving scenarios. The typical laboratory experiment in this tradition consists of a learning phase and a test phase. In the learning phase, students are given some type of instruction or training on a problem or set of problems. In the test phase, students are given some new problem(s) to solve without any of the learning resources (e.g., training materials), constituting a scenario that Bransford and Schwartz (1999) called "sequestered problem solving." Transfer is then measured by improved performance in accuracy or solution time on the test problem compared to a control group that receives some alternative training or no training (see Gick \& Holyoak, 1987, for an overview of this approach). It is argued that this way of defining and testing transfer does not capture many of the real-world aspects of transfer, such as the use of other resources during the test phase or the role of the learning phase in preparing the individual for future learning.

The second critique is that the classical approach relies heavily on models of expert performance; researchers look for "correct" manifestations of transfer according to the experts' perspective. This view has difficulty accounting for the types of reasoning a novice engages in when attempting to transfer knowledge but ultimately failing to generate the expert solution (Lave, 1988; Lobato, 2012). The third criticism is that context is typically defined as the task presented, independent of the students' purposes and construction of meaning in those situations. Very little attention is given to individual differences in how the student frames the activities and how she relates to the learning and test situations. For example, this approach does not examine how individual differences such as prior knowledge outside of the learning phase or motivational dispositions affect transfer.

The fourth criticism is that the classical approach assumes that the knowledge applied is separate from the situations in which it is acquired or used, rather than a function of activity, social interactions, and culture. This point is readily demonstrated by the fact that very few classical studies have measured or systematically manipulated these factors to examine their effects on learning and transfer (cf. see Adams et al., 1988, for an exception of how the type of processing at encoding can impact transfer). Transfer explanations in the classical view focus primarily on the characteristics of the mental representations of the knowledge (e.g., surface vs. structural features) and the cognitive processes involved in applying that knowledge. Little work from this approach has examined how students' motivation, the social situation, and the environmental resources available (e.g., amount of time, affordances of the task) affect the construction of these representations.

\section{ALTERNATIVE APPROACHES: SITUATIVE TRANSFER AND PREPARATION FOR FUTURE LEARNING}

These critiques have received a variety of responses in the field, from a call to abandon the transfer concept entirely (D. W. Carraher \& Schliemann, 2002; Hammer, Elby, Scherr, \& Redish, 2005) to new proposals for how to conceptualize and measure transfer including situative perspectives (Greeno \& MMAP, 1997, 1998; Lave, 1988; see Gruber, Law, Mandl, \& Renkl, 1995, for a review), preparation for future learning (PFL; Bransford \& Schwartz, 1999), and actor-oriented transfer (Lobato, 2012), among others. A common theme of situative approaches is that the analysis shifts from viewing transfer at the level of the individual and his or her knowledge, to a view of transfer as systems of interaction among individuals and the environment, where the individual is but one component of a representation that also includes learning resources, other people, task affordances, and so on (Greeno \& MMAP, 1997, 1998). Transfer from this perspective is thought of as patterns of interaction across situations. Transfer occurs to the degree that the systems of interaction are similar from one situation to another. For example, Greeno and MMAP (1997) examined how students learned and transferred practices of inquiry and communication in using mathematics to solve different kinds of real-world problems. Their analyses focused on the types of interactions between students and teachers (often captured as dialogue) and how these interactions supported transfer.

The unit of analysis is not the individual's prior KCs but instead the interaction of that individual in a particular situation. Critically, situations are not considered simply as information to be included (or not) in a mental representation, as the classical view postulates, but instead as a separate part of the representation of transfer. The classical approach has focused on prior knowledge, task characteristics, and types of processing, but it has ignored the social environment, motivational dispositions and states, and the emergent and dynamic nature of how these processes interact. In contrast, for the situative view the representation itself consists of more than the individual person and includes other people, the instructional materials, resources available, and how the individual interacts with all of these other factors over time.

This approach focuses on the way an individual engages in and develops disciplinary practices in particular learning environments and how the features of those environments support and afford those practices (Brown, Collins, \& Duguid, 1989). It raises questions for how to measure patterns of practice that transfer from one situation to another, and the role that materials, tasks, and other people 
play in those patterns. Much of this work has adopted qualitative methods like ethnography in examining such patterns (e.g., Lave, 1988). Our approach is to address the issues of situative interaction by adapting a classical representational approach but by incorporating components of the social and motivational features of the environment in a framework that can adapt and change over time.

Bransford and Schwartz's PFL approach provides another alternative to the classical view and conceptualizes transfer as using prior knowledge and experience to learn in new situations (Bransford \& Schwartz, 1999; Schwartz et al., 2005). This approach addresses the critique that classical approaches have been too narrow when looking for transfer as improvement in problem solving by the direct application of prior knowledge to a new task. Instead, this approach examines how previous experience can facilitate future learning. Bransford, Schwartz, and colleagues focus on how prior knowledge transfers "into" a new learning situation, affecting how one learns from new materials such as a lecture or a worked example and, in turn, how that affects subsequent performance. This view broadens both the definition of transfer and the methods for how one should go about measuring it. Our approach aims to account for PFL but also to more closely connect that approach to the classical mechanisms.

In the next section we provide a detailed description of our framework, explicating how the mechanisms and processes fit within the framework. We provide three examples that illustrate how the framework can be used to analyze and interpret a variety of student behaviors, and then revisit the criticisms reviewed in this section in light of the framework and the examples. We conclude with a discussion of implications for theory and instruction.

\section{DESCRIPTION OF THE FRAMEWORK}

Central to our view of transfer are the processes of sensemaking and satisficing. Sense-making and satisficing can be viewed as a set of general strategies that influence transfer through the construction of context and the evaluation of potential solutions. We view the four classic mechanisms as a collection of transfer processes that are triggered given particular representations of context. The current framework builds upon and extends our previous work on coordination processes in transfer (Dufresne, Mestre, Thaden-Koch, Gerace, \& Leonard, 2005) and dynamic shifting between multiple mechanisms (Nokes, 2009).

We envision the transfer process in a problem-solving scenario as a cyclical process that the individual follows first in constructing a representation of context and then in generating a solution (see Figure 1 for one way of representing the processes and their subcomponents). Each stage is driven by sense-making, that is, the act of determining whether the task goals have been accomplished to the satisfaction of the solver based on coordination of prior knowledge with infor- mation from the environment and the framing of the task. Evaluative processes take place along the way in which the solver consciously or unconsciously determines if the representation or solution makes sense to that point (satisfies a set of criteria activated by the problem solver); if it does the solver continues, and if it does not the solver backtracks and reevaluates until sense is made. If the solver manages to generate a solution, a solution evaluation takes place that determines if the transfer process will stop or continue. ${ }^{2}$

The evaluative process to determine whether sense has been made is modeled by Simon's notion of satisficing (Simon, 1956, 1993, 1996). Satisficing is the idea that people rarely produce an optimal solution when solving a problem or making a decision but instead generate solutions that simply accomplish their goals. Satisficing is hypothesized to occur as a by-product of the constraints operating on the cognitive system and the environment. Simon (1993) called this type of reasoning "bounded rationality." For example, people have limited memory resources (e.g., working memory capacity) and rarely know all of the potentially relevant solution strategies for a given problem. In addition, making a decision is usually a time-limited activity that places a constraint on the number of alternatives that one can survey and evaluate before a solution must be reached. Furthermore, some environments are ill-structured, where it may not be clear how many alternatives there are, or even what the dimensions are for evaluating those alternatives (e.g., choosing a mate; Todd \& Miller, 1999). Such cognitive and environmental constraints encourage a strategy of satisficing rather than an elaborate search for an optimal solution. Gerd Gigerenzer, Daniel Goldstein, Peter Todd, and their colleagues have pursued a research program to identify and test fast and frugal decision-making heuristics to examine how the mind has adapted to these cognitive and ecological constraints when making decisions (Gigerenzer \& Goldstein, 1996; Gigerenzer, Todd, and the ABC Research Group, 1999). We borrow from and expand upon the ideas of satisficing and bounded rationality and apply them to transfer.

We view the processes of sense-making and satisficing as key to addressing some of the issues and questions raised by the alternative approaches to transfer. Satisficing depends on the interaction between the individual and the environment. Whether the environment is defined as the task affordances, learning setting, or the other individuals present, each of these factors may play a role in determining the criteria upon which an individual will satisfice for a given situation. As a simple example a student may set different satisficing criteria for transfer in different settings. When solving a difficult physics problem on a homework assignment, a student may strive for generating an answer in which she can justify the solution to

\footnotetext{
${ }^{2}$ This final evaluation to determine if sense-making has been achieved can be a careful, conscientious effort encompassing the entire process or a tacit evaluation to determine if things feel $\mathrm{OK}$ and there are no obvious errors or contradictions.
} 


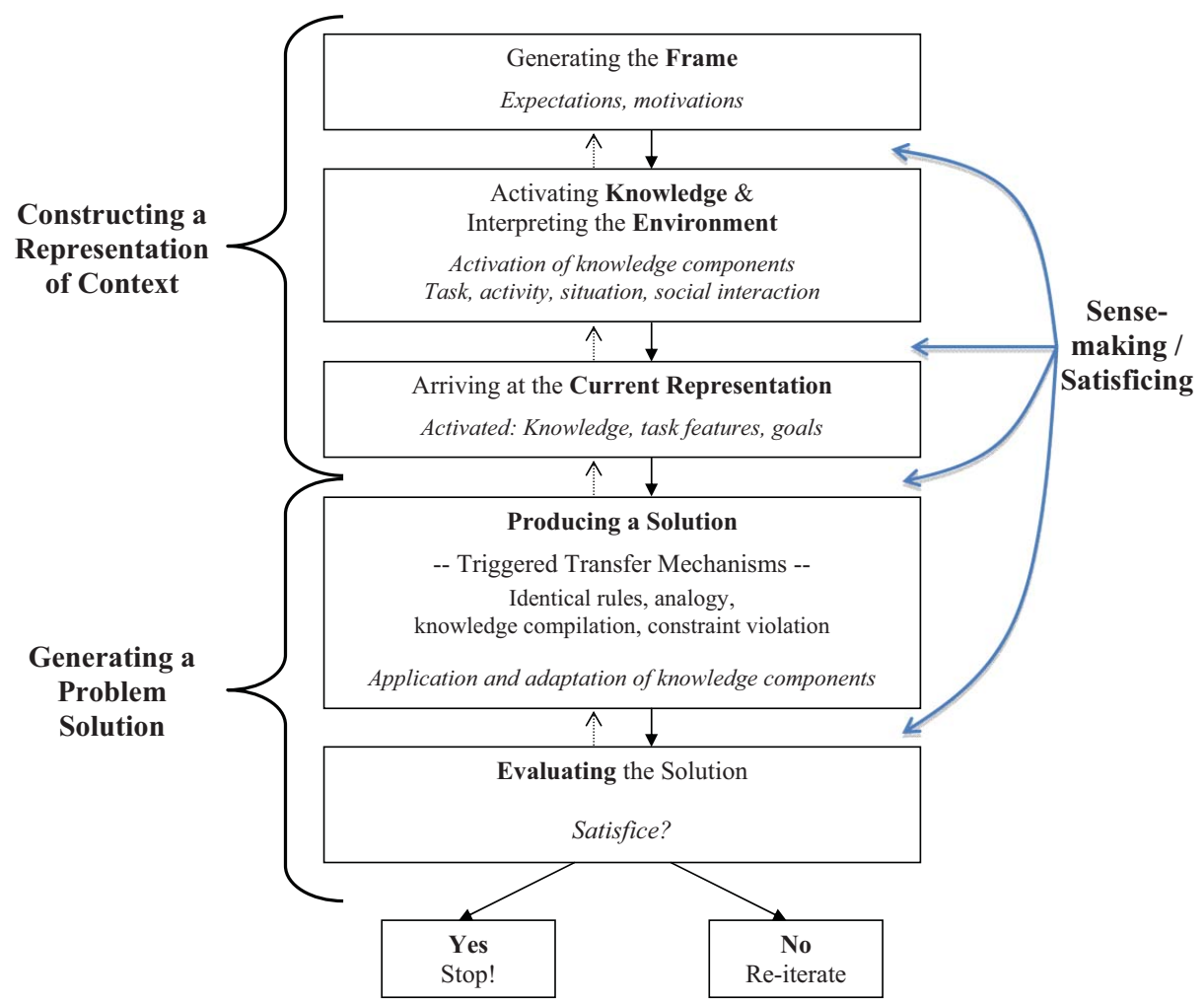

FIGURE 1 Stages of the transfer process for novices solving a problem (color figure available online).

herself by self-explanation. If her first solution attempt results in difficulty self-explaining (e.g., applying what seemed like an appropriate equation from a similar problem), she might try another approach, such as first identifying the physics principle deemed relevant for the problem and then working forward from there. In contrast, that same student, when given the problem as an in-class group assignment, may be satisfied with just making the initial analogy attempt because she does not want to appear like she does not know what she is doing to the other group members by trying other solution approaches.

Critical features of this interaction between the individual and the environment are well captured by research on students' achievement goals. This work has shown that different achievement goals are associated with different criteria for assessing competence on a problem, task, or lesson (Ames, 1992; Dweck \& Leggett, 1988; Elliot, 1999; Harackiewicz, Barron, Pintrich, Elliot, \& Thrash, 2002). Most achievement goal theorists distinguish between two types of goals called mastery and performance. Students with a mastery goal focus on developing understanding and set an internal or absolute standard for evaluating competence, whereas students with a performance goal focus on demonstrating ability and define competence in comparison to others (i.e., a normative standard). Furthermore, each type of goal has been theorized to have either an approach or avoidance orientation (Elliot, 1999). For example, a student with a mastery-approach goal focuses on attaining understanding of a new task or skill, whereas a student with a performance-approach goal focuses on performing better than others. In contrast, a student with a mastery-avoidant goal focuses on not losing her own prior understanding or skill, whereas a performance-avoidant student focuses on not performing poorly compared to other students.

These different goals have clearly different criteria for assessing competence, and in the case of performance goals, they are defined in relation to other people (e.g., the competence criteria is determined by others' performance). These goals can also be promoted by different classroom structures and activities (e.g., Ames, 1992; Urdan \& Schoenfelder, 2006). Furthermore, these goals have been hypothesized to differentially affect transfer. Researchers have proposed that mastery goals should facilitate transfer because they promote a focus on developing understanding and constructive cognitive processes compared to performance goals (Belenky $\&$ Nokes-Malach, 2012; Pugh \& Bergin, 2006). Our framework provides representational features designed to capture students' achievement goals, the associated satisficing criteria, and the implications for transfer.

Our framework builds on and extends some of the core cognitive components captured in Gick's (1986) theory of problem-solving strategies. Gick articulated a general cognitive framework to describe problem solving that included the construction of a mental representation, a solution search 
process, a knowledge application phase, and a mechanism that can revise the representation if the initial solution attempts fail. Our framework builds on these cognitive features (mental representations, search, and knowledge application), but in contrast to Gick's more general problem-solving processes (e.g., means-ends analysis) we focus on the mechanisms involved in the transfer of domain-specific knowledge (i.e., rules, exemplars, strategies, and constraints).

Similar to the other classical mechanisms, Gick's model does not attempt to capture or account for effects of social, motivational, or ecological factors in problem-solving transfer. Instead, it focuses on transfer from the perspective of the individual problem solver and the characteristics of the knowledge representations and processes used to apply that knowledge. In contrast, our framework adds new components of framing, sense-making, and satisficing processes to begin to address the situative issues that Gick's model did not. Incorporating the notion of satisficing into our framework has important implications for answering how, when, and why transfer succeeds or fails. Satisficing serves as a mechanism to explain transfer failures and creates a target of investigation to determine what factors impact students' satisficing criteria. Next we describe the two major stages in the transfer process of constructing a representation of context and generating a solution.

\section{Constructing a Representation of Context}

Transfer begins with the construction of a mental representation of context for the task and situation under consideration. However, before describing the components involved in constructing such a representation, we first elaborate and clarify what we mean by the term context. We view the use of this term as a potential stumbling block to making progress in understanding transfer because different theorists have used it to describe very different aspects of the transfer scenario. Theorists from the classical perspective typically view context as the mental representation of the transfer task (e.g., surface or structural features), whereas situative theorists describe context as referring to both the task features and other aspects of the situation/environment (e.g., other individuals), and importantly as a representation that is outside the head of the learner (e.g., ways of participating). For example, Engle (2006) defined context as including the interactions between a group of students and a teacher and provided an in-depth analysis of their dialogue and the implications for transfer.

To be clear, when we use the term context we are referring to the mental representation of the transfer scenario that includes the task representation as well as the students' framing of the task. Although we adopt the cognitivist approach of focusing on mental representations, it is important to note that our definition is different from the typical classical uses that refer strictly to the features of the transfer task because our conceptualization includes how students frame the task, which is sensitive to motivational, social, and ecological as- pects of the situation. For example, our use of context includes the types of motivational goals and beliefs a student adopts for a given learning situation, such as framing class performance as a competition where the student's goal is to perform better than his or her classmates (e.g., performanceapproach goal; Elliot, 1999). The classical view does not typically include such motivational and social aspects in the representation of context. Next we elaborate on the three components critical to constructing a representation of context: (a) framing, (b) knowledge, and (c) the environment.

Framing. The framing construct was introduced in psychoanalysis, linguistics, and anthropology for describing the mechanisms by which an individual attempts to make sense of a situation (Bateson, 1972; Goffman, 1974; MacLachlan \& Reid, 1994; Tannen, 1993). We use framing similarly to how others in the learning sciences use the term; in framing a situation, the individual attempts to answer the question, "What is going on here?" (Hammer et al., 2005; Hutchison \& Hammer, 2010; Scherr \& Hammer, 2009). To frame a situation, an individual interprets it in terms of similar events or experiences she has had in the past and forms views about what is expected of her. That interpretation can be tacit or explicit and can incorporate sociological (e.g., Should I be polite or argumentative?), epistemological (e.g., Am I supposed to parrot back something the teacher said or figure this out for myself?), or scientific (e.g., Am I expected to analyze this qualitatively from basic principles or generate a quantitative solution?) aspects, among others. In short, a frame is determined for a particular situation by the learner's prior knowledge, motivation, and experiences.

How knowledge is represented and organized in the mind of the user is critical to framing, as this organization will impact which KCs are activated through processes such as spreading activation, by which the activation of one concept facilitates the activation of other semantically related concepts (Anderson, 1983; Collins \& Quillian, 1969). How an individual frames a situation will determine what features of the situation are salient, which in turn impacts what knowledge is activated and applied. Furthermore, the frame that is constructed affects goal setting and the criteria established to evaluate the completion of those goals.

Given that different people can frame the same situation differently, it is not surprising that they apply different knowledge and solution strategies to similar problems. Not only can different people generate different frames, but also the same person can generate different frames depending on the particular features of the situation (Hammer et al., 2005). The examples presented later demonstrate that frames are not static but change as KCs become activated and deactivated.

Different frames may elicit different ways of relating to and participating in new situations. One feature that differentiates our use of frames from more classical uses is that the frame can include different motivational and social 
information such as students' achievement goals (Elliot, 1999). Past research on framing did not include this type of information. Furthermore, we hypothesize that different types of frames can generate different types of satisficing criteria. For example, if a student's frame is to master a homework assignment, then that student might engage in a variety of activities directed toward really understanding the content of the homework, whereas if a student's frame is to avoid performing poorly on the assignment, she may rely on answers in the back of the book or ask a friend for help in finding the right answer. These frames are critical to what knowledge is activated and applied when completing the homework, as well as what transfers to new tasks and situations (such as a classroom test).

Knowledge. At the context representation stage, the framing and situation (e.g., problem attributes, descriptions, etc.) suggests to the learner some previous experience(s) and knowledge that could be relevant based on, for example, similarity at either the surface or structural levels (or both). We hypothesize that prior knowledge is decomposable into KCs. We define KCs as encapsulated units of information. This definition is consistent with other work in the cognitive and learning sciences, including cognitive models such as ACT-R (Anderson \& Lebiere, 1998) and Soar (Newell, 1990), the knowledge in pieces perspectives such as p-prims (diSessa, 1993) and facets (Minstrell, 2001), and the theoretical framework of the Pittsburgh Science of Learning Center (Koedinger, Corbett, \& Perfetti, 2012).

$\mathrm{KCs}$ can vary in representational complexity from single propositional units or rules (i.e., rules that match a single condition and execute a single action such as production rules) to a set of interrelated propositions or rules that exemplify more complex concepts, skills, or procedural knowledge. Of particular importance for our framework is the content of the knowledge representation. Different content plays different roles in the triggering conditions of the classical mechanisms. For example, identical rules transfer requires procedural knowledge, whereas constraint violation requires declarative knowledge in the form of state constraints. The content and representation of these $\mathrm{KCs}$ have implications for what transfer mechanisms are triggered in the generation stage.

Environment. The environmental resources available to the learner affect what KCs are activated as well as the criteria for satisficing. Environmental resources include the nature of the learning and test materials (e.g., type, format, presentation, length, etc.), time available, tools available (e.g., calculator, access to the learning materials at test), and so on. For example, time limitations during transfer may lead to less sophisticated representational strategies than having more time to develop a deep analysis of a problem. We adopt the human factors view that the environment provides both affordances and constraints on transfer (Hutchins, 1995a, 1995b). For example, attempting to solve a math problem with ma- nipulatives (physical objects) may prove easier than solving that same problem without those resources (T. N. Carraher, Carraher, \& Schliemann, 1985). The physical objects can make salient particular relationships or features that then aid in solving the problem (Belenky \& Nokes, 2009; Schwartz \& Martin, 2004).

In addition to the physical environment, the learner functions and transfers in a social environment. This social environment is characterized by the social status and social legitimacy of the learner (Lave \& Wenger, 1991) and the social expectations placed on her. These factors directly influence the act of transfer in terms of (a) extrinsic motivational factors (Lepper \& Greene, 1978), (b) intrinsic motivational factors (Deci, 1975; Malone, 1981), and (c) the behavior deemed appropriate for a given situation (Lave \& Wenger, 1991). For example, social legitimacy provides an environment in which one may feel comfortable offering risky or unusual ideas that facilitate the creative aspects of the declarative transfer process.

Summary of initial construction of context and its evaluation. To summarize this stage, the learner constructs a representation of context by framing the task or situation under consideration and activating potentially fruitful KCs. Which KCs are activated is determined by the dynamic interplay of the learner's prior knowledge, how she or he has framed the task or situation, and the resources in the environment. Having framed the task and activated some general knowledge, the learner constructs an initial representation of context in terms of what is expected (e.g., I'm expected to use knowledge I learned in class to solve this problem) and what type of knowledge might be brought to bear (e.g., I saw the teacher address a similar situation in class, and I may be able to tackle this one in the same way). At some point the learner evaluates, either tacitly or explicitly, whether the representation formed makes sense or satisfices. If the answer is yes, the learner moves to the solution generation stage; if the answer is no, either the situation needs to be framed differently, or new felicitous knowledge needs to be identified (or both), until sense-making or satisficing is achieved. In sum, these components are critical to the interpretation of a task given one's prior knowledge, motivation, and goals.

\section{Generating a Problem Solution}

Based on the current representation of context, KCs will be applied and adapted to generate a solution. Different transfer mechanisms will be triggered for different contexts. The application of KCs may be as simple as applying a rule or as complex as interpreting a piece of declarative knowledge for a new situation. Although we have divided transfer into separate stages of constructing a representation and generating a solution, they are not independent. Generating a solution modifies and updates the current representation of context. This feedback allows the learner to make decisions about the 
transfer progress and (a) continue on the current path, (b) change paths, or (c) end the transfer process. These modifications will impact what future $\mathrm{KCs}$ are activated during the solution process. This decision-making process is governed by the concept of satisficing.

Solution evaluation. To understand and account for the variability and complexity observed in transfer, we need to generate an adequate account of the criteria for satisficing to take place. Following Simon's model, satisficing is determined by the constraints acting on the learner (working memory, prior knowledge, etc.) and the resources available (problem affordances, time available). As the initial conditions for a given task or environment change, the learner presumably uses different criteria to assess an appropriate solution. The learner searches for the solution that satisfies the minimal solution requirements given the criteria for the particular situation (i.e., the quickest path that leads to accomplishing the goal). The criteria for satisficing depends largely on the construction of context, which depends on the frame that was generated, the learner's prior knowledge, and the resources and constraints of the environment. In the next section we describe how the classic mechanisms are triggered under various representational contexts.

Transfer mechanisms. We hypothesize that the particular construction of context results in the application of one or more of the four transfer mechanisms described previously (see Figure 1 for their roles in the transfer process). Each mechanism is hypothesized to be triggered for a given context (Nokes, 2009). A novel contribution of our framework is to bring all of these mechanisms together and relate them to one another. Only when they are taken together and viewed as a set can we begin to account for the diversity and complexity of transfer behaviors observed in the literature. Furthermore, we suggest that there is a trade-off between the cognitive resources required by a given mechanism and its scope of application. Those that facilitate near transfer appear to require fewer cognitive resources than those that facilitate far transfer. In this analysis we focus on the prototypical triggering conditions for a novice problem solver. Our overarching goal is to show that each mechanism represents a feature that a successful model of transfer must incorporate (see Table 1 for a summary).

Identical rules are fast and efficient and are applied automatically; however, they have a relatively narrow scope of application limited to skill-based transfer. Because rule application happens so effortlessly and automatically, we hypothesize that it typically results in tacit satisficing and relatively little conscious reflection to evaluate whether a solution makes sense. However, if one does not have a rule that applies to the situation, then the individual is likely to use other mechanisms and other knowledge to satisfy the evaluation criteria.

Analogy can transfer both procedural and declarative exemplar knowledge but is typically used for near transfer by novices. If procedural components of the exemplar are transferred, the analogical processing is fast and efficient (e.g., Nokes \& Ohlsson, 2005). We hypothesize that the exemplar retrieval stage provides fewer opportunities for explicit

TABLE 1

Table of Transfer Mechanisms and Constraints/Criteria for When They Are Used Successfully by the Novice Problem Solver

\begin{tabular}{|c|c|c|c|c|}
\hline Mechanism & Domain Specific Knowledge & Process & Efficiency & Scope \\
\hline Identical Rules & $\begin{array}{l}\text { Production Rules } \\
\text { (Procedural) }\end{array}$ & $\begin{array}{l}\text { If the condition side of the } \\
\text { rule matches the current } \\
\text { context then the rule is } \\
\text { applied. }\end{array}$ & $\begin{array}{l}\text { Highly efficient, } \\
\text { automatically applied. }\end{array}$ & $\begin{array}{l}\text { Extremely narrow, applies in } \\
\text { situations that match } \\
\text { identical conditions. }\end{array}$ \\
\hline Analogy & $\begin{array}{l}\text { Exemplar Knowledge } \\
\text { (Declarative and } \\
\text { Procedural) }\end{array}$ & $\begin{array}{l}\text { (1) Retrieve an example, (2) } \\
\text { alignment and mapping of } \\
\text { the example to the current } \\
\text { context, (3) drawing an } \\
\text { inference relevant to the } \\
\text { current context. }\end{array}$ & $\begin{array}{l}\text { More similar task } \\
\text { representations will result } \\
\text { in faster alignment and } \\
\text { mapping; if procedural } \\
\text { components transfer, } \\
\text { solution articulation will } \\
\text { be fast. Dissimilar task } \\
\text { representations will either } \\
\text { show a transfer failure or } \\
\text { require additional } \\
\text { processing such as } \\
\text { re-representation. }\end{array}$ & $\begin{array}{l}\text { Novices typically transfer } \\
\text { knowledge to near transfer } \\
\text { problems. }\end{array}$ \\
\hline Knowledge Compilation & $\begin{array}{r}\text { Facts, Instructions, Principles } \\
\text { (Declarative to Procedural) }\end{array}$ & $\begin{array}{l}\text { Interprets declarative } \\
\text { components into specific } \\
\text { problem-solving actions. }\end{array}$ & $\begin{array}{l}\text { Requires many cognitive } \\
\text { resources and is error } \\
\text { prone. }\end{array}$ & $\begin{array}{l}\text { Flexible scope of application, } \\
\text { applies to several problems } \\
\text { within the domain. }\end{array}$ \\
\hline Constraint Violation & $\begin{array}{l}\text { Constraints (Declarative to } \\
\text { Procedural) }\end{array}$ & $\begin{array}{l}\text { Generate-evaluate-revise } \\
\text { transfer cycle. }\end{array}$ & $\begin{array}{l}\text { Requires many iterations of } \\
\text { the transfer cycle to obtain } \\
\text { a satisfactory solution. }\end{array}$ & $\begin{array}{l}\text { Wide scope of application, } \\
\text { typically applies to many } \\
\text { problems in a domain. }\end{array}$ \\
\hline
\end{tabular}


sense-making and satisficing processes than the mapping and inference stages, where there are more opportunities to evaluate the mapping and potentially engage in re-representation of the analogue. This view is consistent with computational models of analogy that model exemplar retrieval with automatic, parallel processes and use more evaluative processes for the later stages of structure mapping and inference generation (e.g., Forbus et al., 1995).

Knowledge compilation transfers declarative knowledge of instructions, facts, or principles and has a wide scope of application, but it requires much cognitive processing to interpret the action implications of that knowledge. We hypothesize that this process provides opportunities for reflective sense-making or satisficing when determining whether the translation was successful in accomplishing the task goals. Constraint violation also can transfer declarative knowledge across a wide variety of situations in a domain but requires much cognitive processing. The probability of generating a correct solution is dependent on many factors including the complexity of the problem and the number of constraints and prior procedures. Because this mechanism incorporates the evaluation of declarative constraints as a component of the process, there are often many opportunities for explicit sense-making or satisficing.

Each mechanism can account for some aspects of transfer but not others. For example, rule application and analogy provide good accounts of different kinds of near transfer (e.g., procedural and declarative) but not far transfer (for novices), whereas declarative-to-procedural mechanisms provide a better account of far transfer. By combining these mechanisms into a single framework driven by sense-making and satisficing processes, we can begin to account for the rich and adaptive transfer performance that a single mechanism could not account for alone.

\section{Evaluation and Interactions Between Mechanisms}

Although much previous research supports the hypotheses of each individual mechanism, relatively few studies have explicitly compared these hypotheses within the same experimental paradigm on the same task. Nokes (2009) has taken some first steps in testing the hypotheses for three of the proposed mechanisms (analogy, knowledge compilation, and constraint violation). In one experiment, students were trained on different types of prior knowledge (exemplars, strategies, or constraints) for a puzzle problem-solving task and then were given a common set of near, intermediate, and far transfer problems to solve. The transfer distance was defined based on a fine-grained analysis of the puzzle surface and structural features. Near transfer was defined as having more similar surface and structural features to the training exemplars, whereas the far transfer problems had a different underlying structure that still followed the domain constraints.

The predictions of each mechanism were supported. Students who were trained on exemplars showed fast and accurate problem solving on near transfer problems, consistent with making analogies to their prior exemplar knowledge and transferring puzzle solving procedures. In contrast, students who were trained on strategies and constraints took longer to transfer their knowledge to the near transfer problems, consistent with predictions of knowledge compilation and constraint violation processes (i.e., both mechanisms require much computational processing to interpret the declarative knowledge). Students in the strategy and constraint training groups also showed evidence of using declarative knowledge on an intermediate transfer problem by generating strategy-specific solutions and solutions consistent with the domain constraints. On the far transfer problems all the training groups struggled to generate successful solutions. Therefore, a second experiment was conducted in which verbal protocols were collected to examine whether students attempted to apply declarative knowledge to the far transfer problems but were just unsuccessful in generating the correct solution.

We predict that if multiple mechanisms are triggered for a given situation, then a person will use the mechanism that requires the least amount of computational processing. This principle of cognitive economy suggests that people will first apply rules, then analogy, then knowledge compilation, and finally constraint violation to the degree that each mechanism can accomplish the transfer goal. In the second experiment from the Nokes (2009) study, students were trained on all three types of prior knowledge (examples, strategies, and constraints) and then solved the same three transfer problems while thinking aloud. Students showed behaviors consistent with making analogies on the near transfer problem (fast and accurate performance similar to Experiment 1), and their verbal protocols showed evidence that they used declarative strategies on the intermediate transfer problem and domain constraints and error-correction (revision) on the far transfer problem. Although overall success on the far transfer problem was poor, students attempted to apply their constraint knowledge to solve the problem. This experiment provided some initial evidence for the cognitive economy hypothesis.

By incorporating sense-making and satisficing processes as the driving engine of transfer, different mechanisms will be triggered for different goals. For example, if the learner's goal criteria are very high (i.e., strive for a solution that can be justified or self-explained) it may prompt the application of additional transfer mechanisms should the first or second attempts fail to meet the goal, whereas someone with a modest goal criteria (i.e., generate a plausible answer) may be satisfied after making an attempt with the least computationally taxing method (i.e., procedural transfer) regardless of whether it succeeds or fails. 


\section{EMPIRICAL EXAMPLES}

In this section we provide several examples to illustrate how the proposed framework can be used to analyze and interpret students' transfer behaviors. These examples have been presented elsewhere at different levels of detail and with different purposes in mind. We have chosen them for several reasons: (a) they have been used to represent various views of transfer including situative (Example 2) and preparation for future learning (Example 3), (b) the participants are novices engaged in problem solving and reasoning on novel problems, (c) they cover different age groups (grade school, high school, and college), and (d) they represent different academic domains (math and science). Our purpose is to illustrate the usefulness of our framework by using it to interpret dynamic student behaviors across all three examples.

\section{Judging the Realism of Motion}

The first example comes from a study by Mestre and colleagues (Dufresne et al., 2005; Mestre, Thaden-Koch, Dufresne, \& Gerace, 2004; Thaden-Koch, Dufresne, \& Mestre, 2006) in which they examined how college students who had completed an honors physics course made predictions and explained the results of a series of physics experiments involving motion. The students' task was to watch video animations of steel balls rolling on steel tracks of varying shapes to determine which of the animations depicted the real motion of the balls. They were given two sets of tracks to make judgments about; each set consisted of an upper track (A) and lower track (B). The first set of tracks was called the "flat-tracks" (Figure 2a), and the second set was called the "V-tracks," named so because the B track resembled the letter V (Figure 2b).

For both the flat-tracks and the V-tracks two steel balls (A $\&$ B) were released from rest at the left end of the apparatus and then finished on the right side at a lower height than the initial height. For each track type the researchers created four false animations that depicted various misconceptions students have about the motion of Ball B (see Figure 2a, 1-4 for the typical misconceptions of the flat-tracks) and one animation that depicted the true motion (animation 5, "Real"). In reality, Ball B wins the race for both the flattracks and the V-tracks by a considerable margin.

For each track type the students were asked to make two rounds of judgments. In the first round they viewed Ball B traveling alone, and in the second round they viewed both Balls $\mathrm{A}$ and $\mathrm{B}$ traveling together in a race scenario. In the case of Ball B traveling alone, students would have to rely on the individual positions and speeds of the ball traveling along the track to make judgments of realism. However, in the case where the balls were released simultaneously and raced along the tracks, the relative position of the balls and/or the individual positions and speeds of the two balls could be used as cues in making judgments about realism. The stu- dents were given a total of four judgment tasks that were presented in the following order: flat-tracks with Ball B traveling alone, V-tracks with Ball B traveling alone, flat-tracks with both balls released simultaneously in a race scenario, and V-tracks with both balls released simultaneously in a race scenario. For each task students were asked to study the animations and then select the one they thought depicted the real motion.

To perform these tasks students could use different types of prior knowledge. Students had no prior experience with this particular task, so we did not expect them to have memorized examples of the animations or a specific procedural rule for which animation to select. However, students could have rule or exemplar prior knowledge for aspects of the motion based on class activities (e.g., observing balls rolling down inclined planes) or from word problems that described similar types of motion. Students could also recall examples of rolling objects from outside of class. Because these students had just completed their honors physics course, they could also use declarative knowledge of relevant physics principles and concepts. For example, students might use their knowledge of the conservation of energy and kinematics concepts to make realism judgments.

In this study a purely classical transfer approach would examine whether there was evidence for a single transfer mechanism. For example, one might look for evidence that students used analogies with examples from class or from everyday experience in their reasoning. This approach would look at the characteristics of the source and target analogues and examine how the source was mapped to the target and what inferences were made. Another classical approach would be to examine whether students tried to apply abstract declarative knowledge of the principles of physics via knowledge compilation for interpreting the realism of the specific animations. That is, researchers would look for evidence that students transferred declarative principles to interpret the animations, make predictions, and generate explanations. It is important to note that each classical approach would look for a single mechanism of transfer when trying to account for how students made their decisions. One of the main points of our framework is that in complex tasks like this one, multiple mechanisms are required to capture the diversity and complexity of the transfer behaviors observed.

We now focus on portions of the transcripts of an honors student (pseudonym Randy); a full transcript can be found in Dufresne et al. (2005). We hope to illustrate not only the use of transfer mechanisms, sense-making, and satisficing processes, but also the fluidity with which students move between transfer mechanisms during explanations as they activate and apply knowledge. We begin by examining Randy's reasoning on the one-ball flat-tracks and then compare his reasoning from that task to his reasoning on the two-ball flattracks. We then skip to his reasoning on the two-ball V-tracks for an illustration of difficulty in satisficing. 


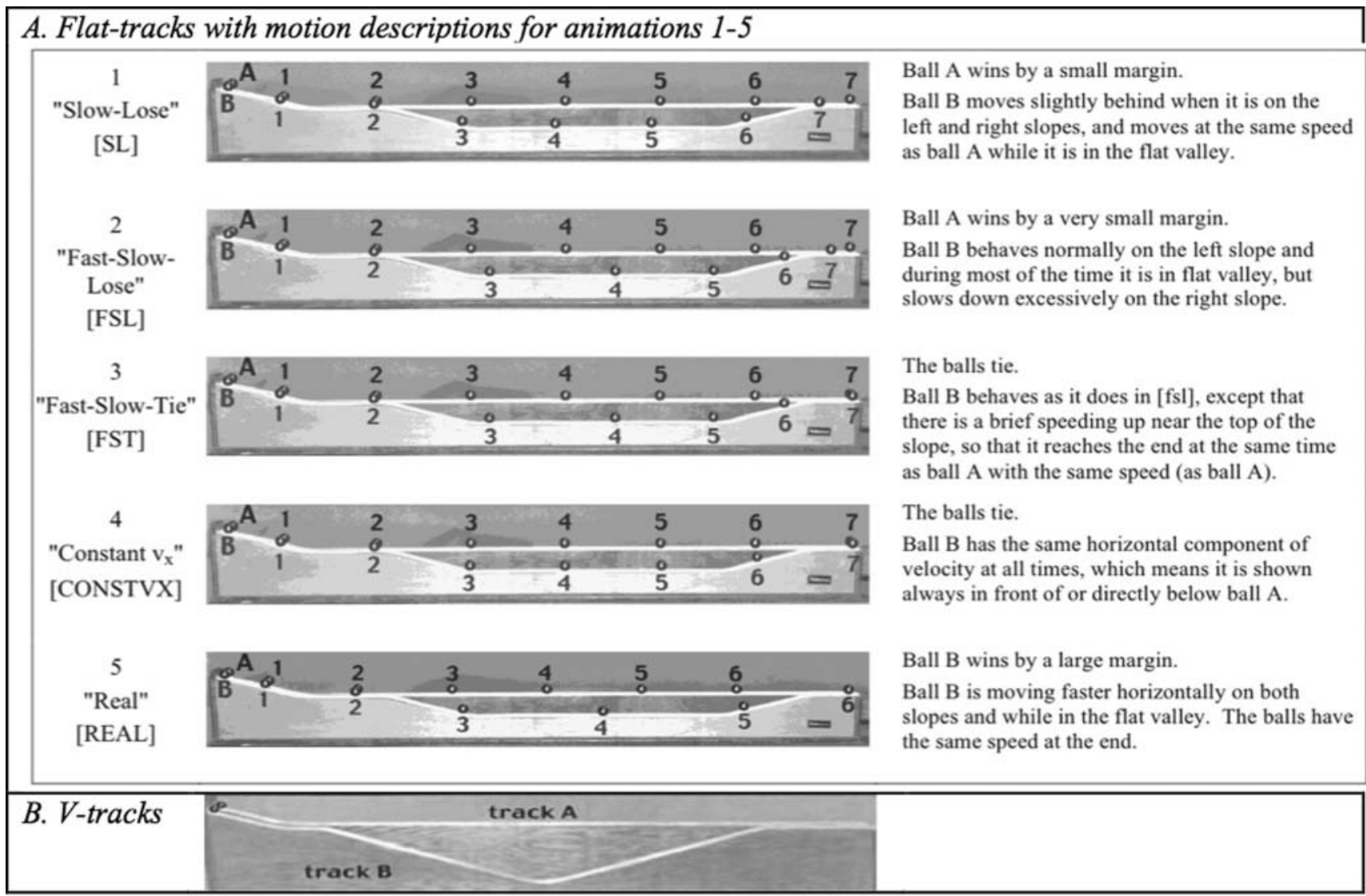

FIGURE 2 Experimental apparatus. (A) shows the flat-tracks with motion descriptions for animations 1-5. (B) shows the V-tracks. Adapted with permission from "Knowledge Representation and Coordination in the Transfer Process," by R. J. Dufresne, J. P. Mestre, T. Thaden-Koch, W. Gerace, and W. Leonard, in J. Mestre (Ed.), Transfer of Learning From a Modern Multidisciplinary Perspective, p. 171. Copyright 2005 by Information Age Publishing.

Reasoning about the flat tracks: Multiple mechanisms and framing. Randy begins making judgments about the realism of the motion in the one-ball flat tracks as follows:

1-2 R: ... Ok, my first question when I look at the first one [SL] is, um, it looks to me, it has a gradual acceleration on the first decline.

$3 \mathrm{I}: \quad \mathrm{Ok}$

4-7 R: But then it looks like the velocity is pretty constant the rest of the way. That bothers me because my intuition tells me that it's gonna have a certain velocity at this horizontal point and a certain higher velocity at this horizontal point. And then at this point it's going to approach, call this $\mathrm{v} 1$ and this $\mathrm{v} 2$, it's gonna approach v1 again.

$8 \mathrm{I}: \quad \mathrm{Ok}$

$9 \mathrm{R}$ : Um, so the first thing I notice is it looks very constant from v1 to v2 they almost, v1 and v2 look the same.

In lines 1 to 2 , identical rules is applied. Randy looks at the first decline and identifies behavior that matches ("it looks to me ...") motion he has seen before in other situations, which he describes as "gradual acceleration" down a sloped surface. Then in lines 4 to 7 and 9, when he evaluates the motion in other parts of the track he switches to constraint violation. Although constraint violation is a three-part process (generate-evaluate-revise), here we see only the first two parts: Randy generates an interpretation of what a ball should do on the second decline and the flat bottom portion, evaluates whether the ball does that, and rejects the animation as unrealistic because it violates the motion constraints he has imposed (speeds should not stay the same during those portions of the track). There is no need to move to the third stage of constraint violation here (revise) because he has accomplished his goal (rejecting the animation based on what he perceives to be anomalous motion) and sense-making has been achieved by rejecting the SL animation as unrealistic. Additional transfer mechanisms are triggered as Randy continues to view other animations.

10-14 R: Um, I'm gonna look at number 2[FSL]. Here, it looks to me as if there is a distinct difference between v1 and v2. I would say v2 is faster than $v 1$. And the reason of course for that reasoning is the sense that in this system we're converting 
potential/gravitational potential energy to kinetic energy, and since the gravitational potential energy is a function of vertical elevation I expect to see an increase in kinetic energy for every degree of fall. So I'm looking for that in this. So I like $2[\mathrm{FSL}]$ better than $1[\mathrm{SL}]$.

$15 \mathrm{I}: \quad \mathrm{Ok}$

16-26 R: Um, uh uh < slight pause> A question is, is there a difference between 2[FSL] and 3[CONSTVX]? $3[\mathrm{CONSTVX}]$ looks a lot like $1[\mathrm{SL}]$ to me, no except maybe it's... Let me see, let me look at 1[SL] again. <pauses, looking at simulation> Yeah, 1[SL] def-, definitely looks like it's being driven by a motor or something, um, 3-3[CONSTVX] looks the same as one to me, ok, without any instruments or anything like that I, I think they look the same. Let's look at 4[FST]. $<$ pauses, looking at simulation $>$ Huh that's very strange. $<$ pauses, looking at simulation again $>$ It looks like it accelerates again when it gets to the top, which is very weird, like there's a magnet on the end or something. That's number $4[\mathrm{FST}]$. Uh, number $4[\mathrm{FST}]<$ or he probably meant to say $5=$ [REAL]> looks like it's accelerating continually throughout the whole thing I don't know but my eye seems to, my eye may be deceiving me, but I think it's getting faster as it progresses regardless of its elevation so I wouldn't chose that either. I think number 2[FSL] is the most realistic.

In lines 10 to 14 Randy relies on knowledge compilation; he activates a concept he learned in physics class (conservation of energy), which he then interprets and unpacks in this particular situation to explain how potential energy is converted into kinetic energy as the ball descends the second decline, resulting in a speeding up of the ball. In lines 17 to 19 and again in 21 to 22 he draws on making analogies to reject two types of motion, one because it looks like it is driven by a motor and the other because it looks like there is a magnet pulling the ball. Note also that on the way to the magnet analogy, constraint violation (“... that's very strange ...") is used in stating that in FST the ball seems to accelerate on the uphill slope as it approaches the final horizontal shelf, which is used to reject this animation as unrealistic. After rejecting the other animations, Randy satisfices on a fake animation depicting the slow-fast motion. Next we briefly describe his reasoning for the two-ball flat tracks to provide a contrast for how adding the motion of Ball $\mathrm{A}$ impacted his reasoning and judgment.

In the two-ball flat tracks task Randy's judgments are radically different than in the one-ball case, guided by the relative positions and speeds of the balls and race outcome (e.g., "I expect their speeds to be different. I expect the lower ball to be faster than the higher ball ..."). He then shows evidence for knowledge compilation by drawing on formal physics knowledge and interprets what this knowledge implies for the motion ("They wouldn't get there at the same time because the integrals of the two velocity functions are unequal."). He then displays constraint violation in rejecting two animations (e.g., "number 4SL is definitely wrong, because the one that stays the highest is fastest"). Finally, he selects the real animation for this task.

In sum, Randy selects a fake animation in the one-ball flat-tracks task and the realistic animation for the two-ball flat-tracks task. His decisions are guided by various transfer mechanisms (i.e., identical rules, analogy, knowledge compilation, and constraint violation) that allow him to achieve sense-making. This example highlights the situative nature of the framing. In the one-ball situation Randy frames the activity as judging the realism of the rolling ball based on how it ought to behave while traveling along the various sections of the track, whereas in the two-ball case he judges the realism in terms of a race (even though many of the same features are present) and applies formal physics knowledge (the integral of velocity graphs) to justify the race outcome. Critically, the framing of each scenario affected what knowledge was transferred and which animation was selected. We now turn to the two-ball V-tracks example as an illustration of a task in which sense-making was much more difficult for Randy to achieve.

Sense-making and satisficing in the two-ball V-tracks scenario. Randy begins the analysis by relying on his prior experiences in judging animations in the previous flat-track tasks and uses analogical reasoning ("ok, this is a similar problem. I throw out number 1 for the same reason. They shouldn't stay abreast of each other.") together with knowledge compilation (". . . but here the integrals of the two functions are equal ... because there is no point where this function is constant"). As Randy works through the problem, he rejects all of the animations except the one in which Ball B speeds up at a point about two thirds of the way on the uphill ramp of the V. Randy sees this anomalous behavior of Ball B, and it bothers him because it violates the constraint that a ball should not speed up going uphill with no apparent cause (“. . . except it accelerates a little bit at the end doesn't it, damn it. Why does it do that? Maybe I don't like any of them. I don't think I like any of them [laughs]"). Randy is clearly bothered by this lack of sense-making. He then goes back and rechecks all the animations he has rejected by playing them again, reaffirming that in his mind they all violate some critical constraint. In the end, he satisfices by picking the FST animation ("I think that 2 is the closest.") but makes it clear that he is satisficing since he has not totally achieved sense-making due to the constraint that has been violated ("I just think there's something wrong with having it accelerate at the end like that, you know?").

This problem-solving task provides a clear illustration of how sense-making drives the application of different transfer mechanisms and the reevaluation of the context for transfer. 
Randy's lack of sense-making causes him to go back and reevaluate the reasons for rejecting each of the previously rejected animations. To do so relies on triggering various mechanisms to generate the reasons for why he should reject a particular animation. We also see a clear example of satisficing as Randy decides to select an animation that he thinks is best (picking the FST animation) given the options and constraints but expresses that he is not happy about that choice. This sense-making drives the application of different transfer mechanisms and the reevaluation of the context for transfer.

Together these excerpts highlight that, although each classical mechanism plays a role in the transfer behaviors that emerge, no single mechanism can account for the entire process. For example, although Randy clearly makes a few analogies, the analogy mechanism alone cannot account for Randy's various error-correction behaviors (i.e., there is little evidence for the claim that he is using exemplars or mapping processes to generate the error corrections). Similarly, the constraint-violation mechanism would have difficulty accounting for Randy's use of prior examples in his reasoning. If we instead treat each mechanism as a separate cognitive tool that can account for a particular type of transfer, we are more likely to capture the full range of transfer behaviors as they dynamically unfold in the task. In addition, no one classical mechanism can account for the sense-making processes that drive Randy to use the different transfer strategies (e.g., shifting from analogy to knowledge compilation). These excerpts also illustrate how different framings in the one-ball and two-ball cases led to different knowledge components being applied as well as different transfer mechanisms.

How would the situative approaches fare in interpreting the transfer occurring in this example? A situative approach would likely provide insight into the patterns of interactions between Randy and the interviewer and the different framings of the one-ball and two-ball scenarios. However, the situative approach would also struggle to provide an account of the instances of the direct application of prior knowledge, which is better captured by the classical mechanisms. For example, it is not clear how situative approaches would account for the direct application of the conservation-of-energy principle to this example. Our framework includes the tools to describe the processes of rule application, analogy, knowledge compilation, and constraint violation. Our framework does a better job than any single one of the other approaches in interpreting these behaviors because important insights from each are brought together and captured by a single framework. Next we examine how the framework applies to a situative example.

\section{Reasoning About Quantities}

The second example comes from a publication by D. W. Carraher and Schliemann (2002) in which they investigated how two fifth-grade students solved problems and reasoned about math concepts. The interviewer (David) structured the questions around a graphical interface, called the Visual Calculator, which showed a visual depiction of the number line and the quantity under consideration (see Figure 3). After the interviewer posed a question or problem such as "What happens if I multiply the quantity U by -1?" the students predicted and explained the result in discussion with each other and the experimenter.

The authors used the resulting interview protocols to argue that researchers should dispense with the classical concept of transfer and instead adopt a more expansive view of learning that takes into account adapting knowledge to new situations vis-à-vis Piagetian assimilation and accommodation. They argued that the classical view of transfer could not account for the dynamic and constructive reasoning behaviors observed in the students' interviews. They interpreted the interviews as providing evidence that the students adapted and adjusted their prior understanding to the particular situations and problems under consideration and that this reasoning was constructed in the moment. They concluded that the reasoning observed in the protocols would be more profitably understood as learning than as knowledge transfer. We analyze a subset of these interview excerpts and discuss how our framework could be applied to the verbal protocols. The purpose is to provide an analysis of the protocols to see what leverage we get from our framework in interpreting the interactions between the students and the interviewer.

David begins the interview by asking the students what would happen if the quantity $U$ were multiplied by minus 1 (see Figure 3, the top line for the problem and the line below it, for the solution). The following excerpt shows the students' responses and illustrates their use of sense-making as they reasoned about the solution. Emily responded to David's question with a solution that is based on identical rules and Tallulah was unsure about the solution.

1-2 David: Here's another thing that you might want to think about. If I put another $\mathrm{U}$ there and multiply it by a minus 1 (I have a special key just for that). All right, who's got a prediction there?

3 Emily: 4-6 David: It won't be anything? It's gonna kinda wipe out? OK ... Emily thinks it won't be anything if you multiply this $\mathrm{U}$ here by minus 1 . What about you? (David realizes the possible confusion between "you" and "U.") I mean Tallulah. That was a bad choice of unit name, wasn't it?

7 Tallulah: $\quad$ Umm, I'm not exactly sure. I guess (inaudible...) I'm not really sure.

8 David (to Emily): OK, so you're saying it will just go away. Negative... sort of like zapping it.

9 Tallulah: Yes. 


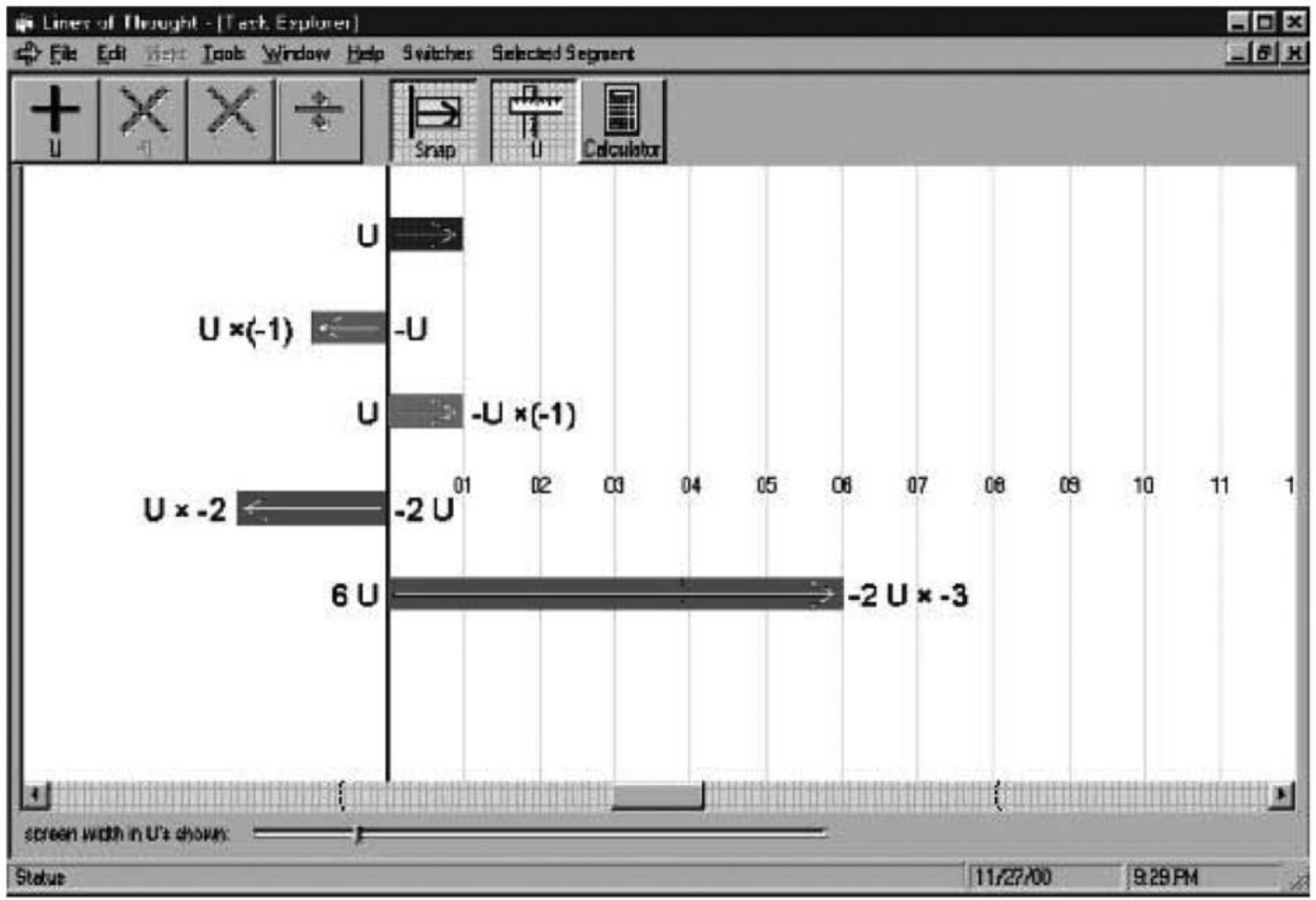

FIGURE 3 Illustration of the Visual Calculator for reasoning about negative multipliers. Reprinted with permission from "The Transfer Dilemma," by D. W. Carraher and A. D. Schliemann, 2002, The Journal of the Learning Sciences, 11(1), p. 7. Copyright 2002 by Lawrence Erlbaum Associates, Inc.

We interpret Emily's response that it will "not be anything" as being based on the application of an overly general rule for adding negative numbers that did not stipulate the appropriate application conditions (i.e., only addition/subtraction operations and not multiplication). In contrast, Tallulah first verbalizes that she is unsure, but then agrees with Emily. We interpret this as satisficing based on not having an alternative suggestion, having an alternative but with high uncertainty, appeasing the task demands in order to move on, or potentially all three.

Next, David asks the two students to find and interpret the answer.

1 David:

Well, go ahead Emily, you click on the minus 1 button there. What happened there?

2 Emily: It's minus 1.

3 David

(extending her phrase): It's minus $1 \mathrm{U}$.

4 Emily:

OK.

5 David:

6 Emily:
7 David:

8-9 Emily:

10 David:

11 Tallulah:
Yes, that's what it is, that's what we're going to use it as.

So everything to the right of it is a whole number and everything to the left of it is like a fractional number sort of, so it's small.

So this is a fraction of a number? Well, yeah because it is smaller than a whole number.

David asks Emily to interpret the solution, specifically asking whether the quantity changed or remained the same. Emily (line 6) describes the solution as less than the quantity before the operation based on interpreting the number line and using the zero as an anchor to guide her interpretation. Emily uses her understanding of the number line to determine the value of the quantity and we interpret this as an instance of knowledge compilation (i.e., interpreting the implications of the number line for the given situation -1U). She then elaborates this solution (lines 8-9) by describing and interpreting everything to the left of zero as a fractional number. When David asks Tallulah if she agrees, she provides further support for the solution vis-à-vis knowledge compilation by interpreting the quantity to the left as smaller than a whole 
number. We identify this as knowledge compilation because they are both interpreting declarative knowledge (i.e., their knowledge of number lines) and articulating the implications for the current situation (i.e., less than a whole number).

David then questions this reasoning by pointing to the 0 and 1 , leading the students to revise their previous statements through what we identify as the first and second stages of constraint violation (generation and evaluation of a solution).

1 David: Is it between zero and one, this thing here?

2 Girls: $\quad$ No.

3 Tallulah: It's a negative number, below zero.

4-5 David: OK, so you're revising your opinion though. You first thought it was a fraction, but now you say it's a negative number.

6 Tallulah: Yes.

7-8 David: It's hard to know how to keep those apart. A fraction seems like less than a whole number, doesn't it?

9 Tallulah: Yes, part of a whole number.

By highlighting the quantity as not being between 0 and 1, David facilitated the students' understanding that calling this quantity a "fraction" violated their prior conception of a fraction as a number between 0 and 1 . This likely led to the realization that whole numbers less than 0 exist. This interpretation is supported by Tallulah's elaboration that "it's a negative number, below zero" (line 3), suggesting error-correction based on her declarative knowledge of whole numbers (Stage 3 of the constraint violation process).

This example highlights the emergence of multiple mechanisms of transfer (identical rules, analogy, knowledge compilation, and constraint violation) as the two students engaged in sense-making of operations using negative multipliers. The framework provides insight into how the students' prior knowledge is brought to bear in interpreting and reasoning about these new tasks. Notice that the shifts between multiple transfer mechanisms are driven by sense-making in an effort to coordinate the environment features (e.g., interpreting the input and output of the Visual Calculator, interviewer hints, and the comments made by the other student) and the students' framing of the situation to accomplish task goals. In addition, although several mechanisms are triggered during the conversation and the students use and adapt their prior knowledge to the current situation, they still make errors along the way (e.g., interpreting $-1 \mathrm{U}$ as a fraction), as judged by a teacher or expert. In this case, the error appears to be a result of misinterpreting (vis-à-vis knowledge compilation) that everything to the left of the 0 on the number line is smaller than a whole number and therefore fractional. David points out the 0 and 1 again, hoping that by highlighting these numbers he will make salient the conceptual relationship between a fraction and a whole number. This pedagogical move is essentially an attempt to reframe the problem. This technique relies upon the assumption that the students know that a fraction exists somewhere between 0 and 1 , and by pointing this out, he highlights the violation of their previous answer (saying $-1 \mathrm{U}$ is a fraction of a number). David thereby supports the construction of a new frame for the problem and the students' inference that whole integers also exist to the left of the 0 but are negative. To understand transfer using this approach we need to make inferences as to the students' frame of reference, their prior knowledge, and the features of the environment that they attend to (task, situation, social context, etc.). An important point to note here is that the social interaction plays a large role in the construction of context. Through questioning as well as highlighting and manipulating features in the environment (e.g., pointing out particular numbers on the graphical interface), David does much to support the generated frames and to facilitate reasoning and transfer.

D. W. Carraher and Schliemann (2002) interpreted these data as evidence for the dynamic, constructive nature of using prior knowledge in new situations. Although we agree with their view that classical approaches could not capture the dynamic constructive nature of transfer, we disagree with their solution of abandoning the concept (as well as the prior cognitive work that has unpacked these processes). A sole focus on knowledge construction in the situation may miss important features for how different types of prior knowledge are applied and adapted to that situation (e.g., identical rules and analogy).

This example does a nice job of illustrating the point that no single classical mechanism can account for the diversity of behaviors observed of Emily and Tallulah and that none of the classical mechanisms can capture the dynamic interactions between the two children, the visual calculator, and the experimenter. D. W. Carraher and Schliemann (2002) illustrated this point with the following quote:

One of our main points is that, at almost every turn, the students are trying to reconcile what they observe happening on screen with rich interpretive schemes. In fact, the degree to which the students adjust their understanding to the cases at hand proves to be the central argument. (p. 9)

Our framework captures this phenomenon as sense-making that drives transfer and results in the triggering of various mechanisms and the application of prior knowledge.

\section{Preparation for Future Learning: The Case of Inventing Statistics}

The third example comes from work by Schwartz, Bransford, and colleagues (Schwartz \& Bransford, 1998; Schwartz et al., 2005; Schwartz \& Martin, 2004) in which they investigate PFL transfer. In a number of clever studies, they investigated transfer in situations in which a learning intervention does not affect immediate performance but instead 
affects subsequent learning and later problem solving. For example, Schwartz and Martin (2004) conducted a study in which high school students learning statistics were given an instructional intervention that consisted of either a form of structured inquiry the authors called invention or a form of direct instruction they called tell-and-practice. This 30-min instructional intervention came in the middle of a statistics lesson and was focused on the concept of standardization. All of the students were given a problem in which they had to determine which of two scores from two different distributions (different means and variances) was more extreme. The students in the invention group were not told any specific method to use when solving the problem and were instructed to try to invent a procedure to help them make a decision. In contrast, the students in the tell-and-practice group were first given an example problem that showed them a procedure (a graphical method) for determining the more extreme score and were told to use it on the problem.

All students then went on to the test phase of the study, taking various assessments on the statistics concepts they were learning and completing a transfer problem on standardization using descriptive statistics instead of raw scores, as they had done in the learning activity. To perform well on this problem, the students had to understand the role of variability in a sample and its relation to individual scores. It is important to note that half of the students in both the invention and telland-practice conditions were given tests that had a worked example for how to calculate and use standardized scores (see Figure 4 for an illustration of the experimental paradigm).

The results showed that students who did not receive the worked example in the test performed poorly on the transfer problem regardless of the initial instruction. The authors

\section{Learning to Compare Data Points across Populations}

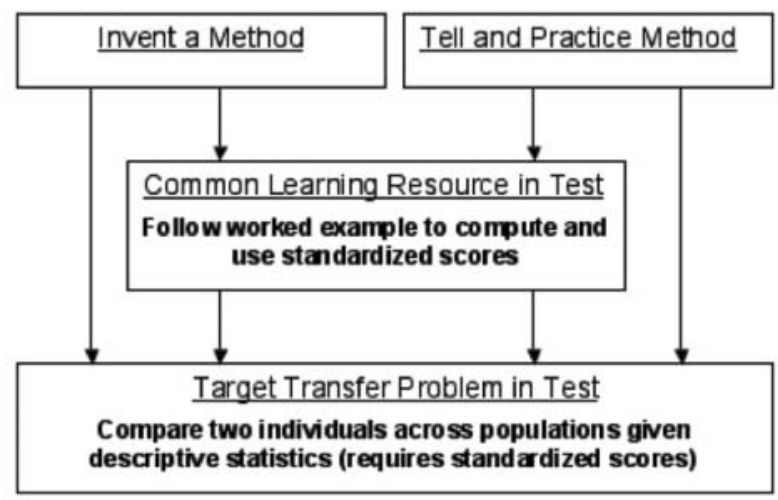

FIGURE 4 The Preparation for Future Learning "double transfer" paradigm used by Schwartz and Martin (2004). Adapted with permission from "Inventing to Prepare for Future Learning: The Hidden Efficiency of Encouraging Original Student Production in Statistics Instruction," by D. L. Schwartz and T. Martin, 2004, Cognition and Instruction, 22(2), p. 149. Copyright 2004 by Lawrence Erlbaum Associates, Inc. compared these results to the classic transfer experiments that have often found null results between conditions. That is, when treating transfer as the direct application of prior knowledge to solve new problems in a sequestered setting, participants showed no gain on transfer (the outside lines of Figure 4). However, among students who were given the worked example in the test, those who received the invention instruction performed well on the transfer task, whereas those given tell-and-practice performed as poorly as the students in the conditions that did not receive the worked example.

The authors interpreted these results as supporting the hidden efficiency of invention in PFL. They hypothesized that students in the invention condition acquired differentiated knowledge - an understanding of various dimensions of the variability concept such as consistency, number of observations, and so on - that prepared them to learn more deeply from the worked example in the test, whereas the students in the tell-and-practice conditions did not. They suggested that students transferred this differentiated knowledge into the subsequent learning situation, which helped them to better understand the worked example. This deeper understanding then facilitated better performance on the standardization problem given in the test.

Our framework provides a way to further explore the possibilities for why PFL works. More specifically, we propose that it gives leverage on the question: What is it about the original learning that helped students acquire differentiated knowledge that in turn impacted subsequent learning and performance? One possible mechanism that may explain these differences is the notion that different types of frames are generated across the two conditions. We hypothesize that the invention condition leads to a focus on understanding the concepts involved in the task (i.e., a mastery achievement goal), whereas the tell-and-practice condition leads to more of a plug-and-chug focus on applying procedures. In some recent work we have found evidence for this hypothesis in that these different instructional conditions actually changed the motivational framing (i.e., achievement goals) of the students involved in the instruction (Belenky \& Nokes-Malach, 2012, 2013). For example, it appears that invention activities helped students to adopt a mastery goal, leading to an enhanced desire to learn and master the target concepts and skills when compared to the students in a tell-and-practice condition. Our main point here is that the framework provides additional concepts not included in the original PFL approach that may prove to be powerful mechanisms.

Our framework may also help to shed light on exactly what types of knowledge were generated in the learning activities. Students in the invention condition may have acquired abstract schemas by comparing and contrasting the cases, whereas students in the tell-and-practice condition were given the information they needed to solve the problem, which may have led to simply memorizing the procedure and applying it mechanically (superficially) to each case. This analysis suggests that the students in the invention condition 
may have acquired a schema-based representation, whereas students in the tell-and-practice condition acquired procedural rules with little abstract declarative knowledge. These different types of knowledge representations have different implications for their scope of application and what transfer mechanisms will be triggered at test.

Furthermore, because the students in the invention condition had to invent a procedure (which no one did with complete success), these students were likely to note the aspects of the problem, procedure, or concept that they were not happy with (i.e., did not make sense or did not satisfice), which then could serve as a cue for accessing that knowledge and example when later confronted with information in the worked example. We believe such cueing when given the worked example would lead to making analogies back to the initial activity. In contrast, the students in the tell-andpractice condition would be less likely to think about the initial learning activity in a deep way when reading the worked example because they were more likely to have satisficed during the first learning activity by achieving a satisfactory solution using the shown procedure.

These conjectures can be tested by asking students in the two conditions to discuss analogical similarities and differences between the worked example in the test and previous examples in the task. We expect that students in the invention condition would be better able to discuss similarities and differences across the two than students in the tell-and-practice condition. In fact, students in the tell-and-practice condition may have studied the worked example in a superficial way because they had already learned a procedure for calculating a similar measure, giving themselves a false belief that they understood the concept.

Such an analysis suggests that it is critical to explore the nature of the knowledge acquired, its representation, and the role it plays in the construction of context. We believe this analysis is consistent with Schwartz, Bransford, and colleagues' general approach and that our framework provides a toolbox to further consider and specify various factors of the constructed representation. Articulating the values and parameters of these factors will help to determine what transfer mechanisms are triggered and how those mechanisms impact future learning and performance. For example, learning experiences that result in the creation of particular knowledge components (e.g., rules, principles, or constraints) may not impact immediate performance on an applicative test (e.g., because a general principle or fact has not been translated into a set of actions or rules for problem solving, or the rules have too narrow a scope of application); however, they may impact new learning in the interpretation or construction of context, which then may trigger different mechanisms of transfer.

\section{Summary of Examples}

Our theoretical framework provides a novel way of capturing the constructive, dynamic, and complex nature of transfer, as well as the manifold processes that unfold in real time. These examples showed that transfer is not a simple application of any single mechanism (e.g., analogy) to a specific task. Instead, to understand the diversity of transfer phenomena we need a model that takes into account the learner's prior knowledge and experiences, how she or he frames the problem, the characteristics of the environment (i.e., task affordances and structure, as well as social situation, tools, etc.), and how she or he makes sense of the solution. Looking across the examples, we can see how different patterns of data (i.e., verbal and behavioral problem-solving phenomena) can be interpreted through a rich theoretical framework that shows how a variety of transfer mechanisms are driven by sense-making and satisficing processes. The students in both mathematics and physics interviews brought knowledge to bear in a number of different ways, including the application of rules, analogical reasoning, interpretation of declarative knowledge (compilation), and constraint violation.

Students in both the mathematics and physics examples made use of formal school knowledge (e.g., negative addends) as well as informal everyday knowledge (e.g., "looks like it's being moved by a magnet"). Both kinds of knowledge were brought to bear in a number of ways, showing that students do not simply rely on prior knowledge they learned in class. These examples also illustrate the importance of social aspects of the interactions during the experiment (i.e., interviewer prompts and behaviors) for transfer. In the negative numbers example, the experimenter manipulated the environment that facilitated a reframing of the problem and gave feedback in such a way that it afforded the emergence of particular transfer processes such as constraint violation. He then helped to scaffold, build, and elaborate the students' reasoning around those affordances.

In addition, the sense-making framework provides a connection to the PFL paradigm and a set of mechanisms to further explore what processes underlie the transfer effects. The framework also raises new questions about the role of framing criteria in PFL studies. Under particular conditions (e.g., invention task) students may not be satisfied with their own solutions until they encounter future instruction that helps them resolve their own confusion and better construct an understanding of the target concepts, whereas tell-andpractice instruction may facilitate an "I know the answer" criterion that leads to shallow processing when encountering a new, related example or concept.

\section{WORKING TOWARD A MODEL}

The examples just provided show how the framework could be used to help interpret a variety of transfer behaviors that previous classical or situated approaches could not account for individually. The examples were meant to be illustrative of the usefulness of the framework. In this section we discuss how one would test the framework and move toward the 
development of a model. As a first step we suggest further testing of two central components of the framework: (a) the multiple mechanisms hypothesis and (b) how frames impact sense-making and satisficing processes in transfer.

Let us first take the postulate that there are multiple classical mechanisms of transfer triggered in various contexts. As we discussed in the introduction and theoretical description sections, there is extensive evidence for the existence of each of the classical mechanisms, including much work on when and how those particular mechanisms are triggered. However, there is relatively little work on how the mechanisms interact with one another and which mechanisms are triggered when they are competing across varying situations. In addition, future research should further test and explore the cognitive economy hypothesis to see whether the cognitive architecture is biased to select and apply transfer mechanisms that require less computational processing before those requiring more, and to determine under what conditions such a relationship might apply.

Although Nokes (2009) has taken the first steps in exploring the interaction of various classical mechanisms, this work needs to be expanded to include other mechanisms (e.g., identical rules) and academic domains (e.g., mathematics and science learning). A current limitation of this component of the framework is that the prior work that has examined each mechanism separately has also made different assumptions about how knowledge is represented and processed (e.g., production rules vs. connectionist representations) and has instantiated the different mechanisms using different computational modeling approaches. A major hurdle for future work is to develop a computational model that includes all of the mechanisms in a single system to predict transfer.

The second major component of the framework that needs to be tested is the hypothesis that different framings of the situation can trigger different sense-making and satisficing processes. This component is critical for bridging to alternative perspectives of transfer, in that frames are hypothesized to capture various motivational and social aspects of the transfer scenario. If particular frames can be connected to various satisficing criteria, then we can predict the types of cognitive processing that those frames afford for a particular situation. Recent work on the impact of framing in learning scenarios provides some exciting evidence for the effects of frames on cognition and behavior. For example, David Hammer and colleagues (Hammer et al., 2005) examined epistemological framings of students learning physics and found that identifiable frames (e.g., school-based knowledge and out-of-school knowledge) were associated with particular types of transfer behaviors. Recent work has also begun to look at the implication of different frames for instruction and knowledge transfer (Engle, Nguyen, \& Mendelson, 2011; Engle, Lam, Meyer, \& Nix, 2012). In this work Engle and her colleagues examined how "expansive" and "bounded" framing impact student learning and transfer in very different ways. Future work should help establish how particular frames affect the criteria that students adopt for satisficing, and in turn how sense-making and satisficing guide the transfer process. Furthermore, research should show how particular frames trigger specific combinations of classical cognitive mechanisms. If such research determines that manipulating the criteria for satisficing does not impact the likelihood of triggering particular classical mechanisms, then this would serve as evidence to falsify that component of the framework.

\section{CONCLUSION}

In this article we propose a new theoretical framework to help analyze and interpret the diversity of transfer phenomena. The framework integrates classical mechanisms and draws on sense-making and satisficing processes to provide the monitoring functions of the transfer cycle. The cycle consists of two parts. The first part is constructing a representation of context that depends on a learner's framing of the situation, problem, or task; his or her prior knowledge; the affordances of the task or activity; the resources available; and the social environment. Each of these factors impacts the construction of the representation. The second part is generating a problem solution, which depends on the learner's application and adaptation of knowledge components (i.e., identical rules, exemplars, strategies, and constraints). Which transfer processes are triggered depends on the particular representation of context. Students then evaluate whether their solutions make sense and/or satisfice for the particular context, which in turn can trigger subsequent mechanisms. These stages are not independent, with the solution generation process impacting the representation of context and vice versa.

This framework begins to address common criticisms of the classical approach (Greeno, 2006; Lave, 1988; Lobato, 2006) by (a) examining a broad definition of transfer, focusing on the construction and application of knowledge in problem-solving scenarios; (b) relying on models of novice performance that can lead to transfer failures as well as successes; (c) taking into account students' purposes and construction of meaning in those situations (i.e., how she or he frames the problem and makes sense of the solution); and (d) assuming that the knowledge constructed and applied is integral to the situations in which it is acquired or used, which in turn is a function of activity and social interactions. We provided examples of student problem solving in mathematics and physics to illustrate how the framework can capture transfer across a variety of situations. We end with brief remarks about the implications of the framework for theory development of higher order cognitive processes and for instruction.

\section{Implications for Theory}

We view this framework as an effort to build upon and extend the classical cognitive view by incorporating multiple 
mechanisms of transfer that are dynamically triggered from a general transfer cycle. Our attempt here centered around a set of strategies that rely on sense-making and satisficing to determine when the transfer processes begin and end. This framework begins to address the questions and issues raised by the alternative approaches. Although our framework does not incorporate analysis at the situative level of the activity system (Greeno \& MMAP, 1997), we see the current work's emphasis on framing in the construction of context and sense-making as providing a foundation upon which a bridge to situative approaches can be built. For progress to be made in understanding complex higher order cognitive processes such as transfer, it is important to interrelate and eventually integrate the key insights and work from these two traditions into a model that specifies how they fit together.

\section{Implications for Instruction}

It is important to highlight that our framework affords an analysis of transfer that is descriptive of reasoning patterns as they unfold in time. This helps to identify the components to be included in a successful model of transfer. If a model were developed based on this framework, it would minimally require specifying learner factors (prior knowledge, experience, motivation), situational factors (framing, task, available tools, social interaction), and the evaluative functions of sense-making and satisficing to have predictive power. This specification would facilitate predicting what transfer mechanisms are triggered, and based on those mechanisms one could predict the type of reasoning and behavior used by the student.

The framework raises questions about the type of transfer we want to encourage and facilitate in our classrooms. For example, if we want students to draw particular connections and make analogies, then the student should be supplied with the right kinds of cues, gestures, or questions (e.g., Richland, Stigler, \& Holyoak, 2012). If we want students to acquire skills and apply rules, then we should structure the task in ways that afford these outcomes (e.g., Anderson et al., 1989). If the goal is to have students reason with declarative knowledge in different situations, then we need to provide the proper scaffolding to support knowledge compilation and constraint violation (e.g., Mitrovic, 2012; Ohlsson, 1992). If we want students to generate frames that encourage deep processing and far transfer, then we need to identify and use activities that facilitate sense-making and mastery goals (e.g., Belenky \& Nokes-Malach, 2012, 2013).

The examples provided earlier demonstrate that students have the potential to bring to bear a wide variety of transfer mechanisms when tackling complex cognitive tasks. One implication of this observation is that pedagogy that supports the construction of a diversity of contexts should promote the application of multiple mechanisms at test. For example, by designing instruction to include a variety of learning materials and activities such as problem-solving practice, worked example study, self-explanation, interactive discussion, and so on, instructors can give students the opportunity to construct the knowledge required for triggering different mechanisms. Determining which types of instruction and activities to include will of course depend on both the types of transfer behaviors and assessments desired and the practical constraints of a school's curriculum, policy, and practices. This raises important empirical questions about which types of instruction to combine as well as how to combine them (e.g., timing and sequencing). To explore some of these issues we have been developing and testing instructional materials for students learning introductory physics in which we integrate a variety of instructional techniques including studying worked examples, problem comparison, and generating explanations in the context of problem solving (Mestre, Docktor, Strand, \& Ross, 2011; Mestre, Ross, Brookes, Smith, \& Nokes, 2009).

The framework also raises questions about the possibility of instructing or modeling processes of framing and sensemaking for students. It is possible that direct instruction and training in sense-making activities could further promote the development of these skills and abilities for transfer. Instruction that facilitates open class discussion and evaluation of ideas by students and teachers may promote effective sensemaking in a class setting. This idea is consistent with recent research on "accountable talk," which investigates how various forms of structured classroom dialogue can support student learning and transfer (e.g., Resnick, Michaels, \& O'Connor, 2010).

In addition to considering how different types of instruction relate to the construction of context and sense-making, we should also consider how different types of assessments relate to the triggering conditions of the classical mechanisms. For example, students given instruction to promote learning algebraic procedures are poorly prepared for a conceptual assessment in which the teacher expects transfer to a qualitative reasoning task, whereas a better matched assessment would be to expect transfer to solving a new problem that required the quick and error-free application of those same procedures. In contrast, instruction designed to facilitate declarative knowledge of mathematics concepts and principles would be poorly matched to the procedural assessment task (as students may make errors interpreting those concepts) but better matched to the qualitative reasoning task. Different types of assessments will be more or less well suited to the triggering conditions of various mechanisms. Framing is also likely to be critical at assessment. For example, students will frame a high-stakes standardized test much differently than a low-stakes assessment in the form of a group project (e.g., with frames ranging from viewing the assessment as a measure of ability to positioning students as authors ready to engage in disciplinary reasoning). These different frames will then affect students' construction of context and subsequent transfer. We encourage teachers to consider the explicit and implicit framings of their 
assessments and how they relate to students' sense-making and satisficing criteria. Using multiple assessments with an array of triggering conditions and giving careful consideration to the framing of those assessments should aid in capturing the diversity of student reasoning and behavior examined in the classroom.

\section{ACKNOWLEDGMENTS}

This work was supported by Grant SBE0354420 from the National Science Foundation, Pittsburgh Science of Learning Center (http://www.learnlab.org) and Grant R305B070085 from the Department of Education, Institute of Education Sciences. No endorsement should be inferred. We thank Vincent Aleven, David T. Brookes, Clark Chinn, Stellan Ohlsson, James Greeno, Sarah Nokes-Malach, members of Cognitive Science Learning Laboratory, and three anonymous reviewers for their many helpful comments and suggestions on the paper.

\section{REFERENCES}

Adams, L. T., Kasserman, J. E., Yearwood, A. A., Perfetto, G. A., Bransford, J. D., \& Franks, J. J. (1988). Memory access: The effects of fact-oriented versus problem-oriented acquisition. Memory \& Cognition, 16, 167-175. doi:10.3758/BF03213486

Alfieri, L., Nokes-Malach, T. J., \& Schunn, C. D. (2013). Learning through case comparisons: A meta-analytic review. Educational Psychologist, 48, 87-113. doi:10.1080/00461520.2013.775712

Ames, C. (1992). Classrooms: Goals, structures, and student motivations. Journal of Educational Psychology, 84, 261-271. doi:10. 1037/0022-0663.84.3.261

Anderson, J. R. (1982). Acquisition of cognitive skill. Psychological Review, 89, 369-406. doi:10.1037/0033-295X.89.4.369

Anderson, J. R. (1983). A spreading activation theory of memory. Journal of Verbal Learning and Verbal Behavior, 22, 261-295. doi:10. 1016/S0022-5371(83)90201-3

Anderson, J. R. (1987). Skill acquisition: Compilation of weak-method problem solutions. Psychological Review, 94, 192-210. doi:10.1037/0033295X.94.2.192

Anderson, J. R., Conrad, F. G., \& Corbett, A. T. (1989). Skill acquisition and the LISP Tutor. Cognitive Science, 13, 467-506. doi:10. 1207/s15516709 $\operatorname{cog} 1304 \_1$

Anderson, J. R., Finchman, J. M., \& Douglas, S. (1997). The role of examples and rules in the acquisition of a cognitive skill. Journal of Experimental Psychology: Learning, Memory, and Cognition, 23, 932-945. doi: $10.1037 / 0278-7393.23 .4 .932$

Anderson, J. R., Greeno, J. G., Kline, P. J., \& Neves, D. M. (1981). Acquisition of problem-solving skill. In J. R. Anderson (Ed.), Cognitive skills and their acquisition (pp. 191-230). Hillsdale, NJ: Erlbaum.

Anderson, J. R., \& Jeffries, R. (1985). Novice LISP users: Undetected losses of information from working memory. Human Computer Interaction, 1, 107-131. doi:10.1207/s15327051hci0102_2

Anderson, J. R., \& Lebiere, C. (1998). The atomic components of thought. Mahwah, NJ: Erlbaum.

Bassok, M. (1990). Transfer of domain-specific problem-solving procedures. Journal of Experimental Psychology: Learning, Memory, and Cognition, 16, 522-533. doi:10.1037/0278-7393.16.3.522
Bassok, M., \& Holyoak, K. J. (1989). Interdomain transfer between isomorphic topics in algebra and physics. Journal of Experimental Psychology: Learning, Memory, and Cognition, 15, 153-166. doi:10.1037/h0090398

Barnett, S. M., \& Ceci, S. J., (2002). When and where do we apply what we learn? A taxonomy for far transfer. Psychological Bulletin, 128, 612-637. doi:10.1037/0033-2909.128.4.612

Bateson, G. (1972). Steps to an ecology of mind: Collected essays in anthropology, psychiatry, evolution, and epistemology. San Francisco, CA: Chandler.

Bechtel, W. (2008). Mechanisms in cognitive psychology: What are the operations? Philosophy of Science, 75, 983-994. doi:10.1086/594540

Belenky, D. M., \& Nokes, T. J. (2009). Examining the role of manipulatives and metacognition on engagement, learning, and transfer. Journal of Problem Solving, 2, 102-129.

Belenky, D. M., \& Nokes-Malach, T. J. (2012). Motivation and transfer: The role of mastery-approach goals in preparation for future learning. The Journal of the Learning Sciences, 21, 399-432. doi:10. 1080/10508406.2011.651232

Belenky, D. M., \& Nokes-Malach, T. J. (2013). Mastery-approach goals and knowledge transfer: An investigation into the effects of task structure and framing instructions. Learning and Individual Differences, 25, 21-34. doi:10.1016/j.lindif.2013.02.004

Bovair, S., Kieras, D. E., \& Polson, P. G. (1990). The acquisition and performance of text-editing skill: A cognitive complexity analysis. Human-Computer Interaction, 5, 1-48. doi:10.1207/ s15327051hci0501_1

Bransford, J. D., \& Schwartz, D. L. (1999). Rethinking transfer: A simple proposal with multiple implications. Review of Research in Education, 24, 61-100. doi:10.3102/0091732×024001061

Brown, J. S., Collins, A., \& Duguid, P. (1989). Situated cognition and the culture of learning. Educational Researcher, 18, 32-42. doi: $10.3102 / 0013189 \times 018001032$

Card, S. K., Moran T. P., \& Newell, A. (1983). The psychology of human-computer interaction. Hillsdale, NJ: Erlbaum.

Carraher, D. W., \& Schliemann, A. D. (2002). The transfer dilemma. The Journal of the Learning Sciences, 11, 1-24. doi:10.1207/ S15327809JLS1101_1

Carraher, T. N., Carraher, D. W. \& Schliemann, A. D. (1985). Mathematics in the streets and in schools. British Journal of Developmental Psychology, 3, 21-29. doi:10.1111/j.2044-835X.1985.tb00951.x

Chen, Z. (2002). Analogical problem solving: A hierarchical analysis of procedural similarity. Journal of Experimental Psychology: Learning, Memory, and Cognition, 28, 81-98. doi:10.1037/0278-7393.28.1.81

Collins, A. M., \& Quillian, M. R. (1969). Retrieval time from semantic memory. Journal of Verbal Learning and Verbal Behavior, 8, 240-247. doi:10.1016/S0022-5371(69)80069-1

Craver, C. F., \& Bechtel, W. (2006). Mechanism. In S. Sarkar \& J. Pfeifer (Eds.), Philosophy of science: An encyclopedia (pp. 469-478). New York, NY: Routledge.

Day, S. B., \& Goldstone, R. L. (2012). The import of knowledge export: Connecting findings and theories of transfer of learning. Educational Psychologist, 47, 153-176. doi:10.1080/00461520.2012.695710

Detterman, D. K., \& Sternberg, R. J. (Eds.). (1993). Transfer on trial: intelligence, cognition, and instruction. Norwood, NJ: Ablex.

Deci, E. L. (1975). Intrinsic motivation. New York, NY: Plenum.

diSessa, A. A. (1993). Toward an epistemology of physics. Cognition and Instruction, 10, 105-225. doi:10.1080/07370008.1985.9649008

Docktor, J. L., Mestre, J. P., \& Ross, B. H. (2012). Impact of a short intervention on novices' problem categorization criteria. Physical Review Special Topics-Physics Education Research, 8, 020102. doi:10.1103/PhysRevSTPER.8.020102

Dufresne, R. J., Mestre, J. P., Thaden-Koch, T., Gerace, W., \& Leonard, W. (2005). Knowledge representation and coordination in the transfer process. In J. Mestre (Ed.), Transfer of learning from a modern multidisciplinary perspective (pp. 155-215). Greenwich, CT: Information Age. 
Dweck, C. S., \& Leggett, E. L. (1988). A social-cognitive approach to motivation and personality. Psychological Review, 95, 256-273. doi:10. 1037/0033-295X.95.2.256

Elliot, A. J. (1999). Approach and avoidance motivation and achievement goals. Educational Psychologist, 34, 169-189. doi:10.1207/ s15326985ep3403_3

Engle, R. A. (2006). Framing interactions to foster generative transfer: A situative explanation of transfer in a community of learners classroom. Journal of the Learning Sciences, 15, 451-498. doi:10.1207/s15327809j1s1504_2

Engle, R. A., Lam, D. P., Meyer, X. S., \& Nix, S. E. (2012). How does expansive framing promote transfer? Several proposed explanations and a research agenda for investigating them. Educational Psychologist, 47, 215-231. doi:10.1080/00461520.2012.695678

Engle, R. A., Nguyen, P. D., \& Mendelson, A. (2011). The influence of framing on transfer: initial evidence from a tutoring experiment. Instructional Science, 39, 603-628. doi:10.1007/s11251-010-9145-2

Forbus, K. D., Gentner, D., \& Law, K. (1995). MAC/FAC: A model of similarity-based retrieval. Cognitive Science, 19, 141-205. doi:10.1207/s15516709 $\operatorname{cog} 1902 \_1$

Gentner, D. (1983). Structure-mapping: A theoretical framework for analogy. Cognitive Science, 7, 155-170. doi:10.1207/s15516709 $\operatorname{cog} 0702 \_3$

Gentner, D., Holyoak, K. J., \& Kokinov, B. N. (Eds.). (2001). The analogical mind. Cambridge, MA: MIT Press.

Gick, M. L. (1986). Problem-solving strategies. Educational Psychologist, 21,99-120. doi:10.1080/00461520.1986.9653026

Gick, M. L., \& Holyoak, K. J. (1980). Analogical problem solving. Cognitive Psychology, 12, 306-355. doi:10.1016/0010-0285(80)90013-4

Gick, M. L., \& Holyoak, K. J. (1983). Schema induction and analogical transfer. Cognitive Psychology, 15, 1-38. doi:10.1016/ 0010-0285(83)90002-6

Gick, M. L. \& Holyoak, K. J. (1987). The cognitive basis of knowledge transfer. In S. M. Cormier \& J. D. Hagman (Eds.), Transfer of learning: Contemporary research and applications (pp. 9-46). New York, NY: Academic Press.

Gigerenzer, G., \& Goldstein, D. G. (1996). Reasoning the fast and frugal way: Models of bounded rationality. Psychological Review, 103, 650-669. doi:10.1037/0033-295X.103.4.650

Gigerenzer, G., Todd, P. M., \& the ABC Research Group (1999). Simple heuristics that make us smart. New York, NY: Oxford University Press.

Goffman, E. (1974). Frame analysis: An essay on the organization of experience. Cambridge, MA: Harvard University Press.

Greeno, J. G., \& the Middle-School Mathematics through Applications Project Group. (1997). Theories and practices in thinking and learning to think. American Journal of Education, 106, 85-126. doi:10.1086/ 444177

Greeno, J. G., \& the Middle-School Mathematics through Applications Project Group. (1998). The situativity of knowing, learning, and research. American Psychologist, 53, 5-26. doi:10.1037/0003-066X.53.1.5

Greeno, J. G. (2006). Authoritative, accountable, positioning and connected general knowing: Progressive themes in understanding transfer. The Journal of the Learning Sciences, 15, 537-547. doi:10.1207/s15327809j1s1504_4

Gruber, H., Law, C., Mandl, H., \& Renkl, A. (1995). Situated learning and transfer: State of the art. In P. Reimann \& H. Spada (Eds.), Learning in humans and machines: Towards an interdisciplinary learning science (pp. 168-188). Oxford, UK: Pergamon.

Hammer, D., Elby, A., Scherr, R. E., \& Redish, E. F. (2005). Resources, framing, and transfer. In J. Mestre (Ed.), Transfer of learning from a modern multidisciplinary perspective (pp. 89-119). Greenwich, CT: Information Age.

Harackiewicz, J. M., Barron, K. E., Pintrich, P. R., Elliot, A. J., \& Thrash, T. M. (2002). Revision of achievement goal theory: Necessary and illuminating. Journal of Educational Psychology, 94, 638-645. doi:10.1037/00220663.94.3.638
Hardiman, P. T., Dufresne, R., \& Mestre, J. P. (1989). The relation between problem categorization and problem solving among experts and novices. Memory \& Cognition, 17, 627-638. doi:10.3758/BF03197085

Hofstadter, D., \& Mitchell, M. (1994). The copycat project: A model of mental fluidity and analogy-making. In K. J. Holyoak \& J. A. Barden (Eds.), Advances in connectionist and neural computation theory volume 2: Analogical connections (pp. 31-112). Norwood, NJ: Ablex.

Holyoak, K. J., \& Thagard, P. (1989). Analogical mapping by constraint satisfaction. Cognitive Science, 13, 295-355. doi:10.1207/ s15516709 $\operatorname{cog} 1303 \_1$

Hummel, J. E., \& Holyoak, K. J. (1997). Distributed representations of structure: A theory of analogical access and mapping. Psychological Review, 104, 427-466. doi:10.1037/0033-295X.104.3.427

Hutchins, E. (1995a). Cognition in the wild. Cambridge, MA: The MIT Press.

Hutchins, E. (1995b). How a cockpit remembers its speed. Cognitive Science, 19, 265-288. doi:10.1207/s15516709 $\operatorname{cog} 1903 \_1$

Hutchison, P., \& Hammer, D. (2010). Attending to student epistemological framing in a science classroom. Science Education, 94, 506-524. doi: $10.1002 /$ sce. 20373

Keane, M. T., Ledgeway, T., \& Duff, S. (1994). Constraints on analogical mapping: A comparison of three models. Cognitive Science, 18, 387-438. doi:10.1207/s15516709 $\operatorname{cog} 1803 \_2$

Kieras, D. E., \& Bovair, S. (1986). The acquisition of procedures from text: A production system analysis of transfer of training. Journal of Memory and Language, 25, 507-524. doi:10.1016/0749-596X(86)90008-2

Kieras, D., \& Polson, P. G. (1985). An approach to the formal analysis of user complexity. International Journal of Man-Machine Studies, 22, 365-394. doi:10.1016/S0020-7373(85)80045-6

Koedinger, K. R., Corbett, A. T., \& Perfetti, C. (2012). The KnowledgeLearning-Instruction (KLI) framework: Bridging the science-practice chasm to enhance robust student learning. Cognitive Science, 36, 757-798. doi:10.1111/j.1551-6709.2012.01245.x

Lave, J. (1988). Cognition in practice. Cambridge, MA: Cambridge University Press.

Lave, J., \& Wenger, E. (1991). Situated learning: Legitimate peripheral participation. Cambridge, MA: Cambridge University Press

Lepper, M. R., \& Greene, D. (Eds.). (1978). The hidden costs of reward. Hillsdale, NJ: Erlbaum.

Lobato, J. (2006). Alternative perspectives on the transfer of learning: History, issues, challenges for future research. Journal of the Learning Sciences, 15, 431-449. doi:10.1207/s15327809jls1504_1

Lobato, J. (2012). The actor-oriented transfer perspective and its contributions to educational research and practice. Educational Psychologist, 47, 232-247. doi:10.1080/00461520.2012.693353

MacLachlan, G. L., \& Reid I. (1994). Framing and interpretation. Melbourne, Australia: Melbourne University Press.

Malone, T. W. (1981). Toward a theory of intrinsically motivating instruction. Cognitive Science, 5, 333-369. doi:10.1207/s15516709 $\operatorname{cog} 0504 \_2$

Mestre, J., Docktor, J. L., Strand, N. E., \& Ross, B. H. (2011). Conceptual problem solving in physics. In J. P. Mestre \& B. H. Ross (Eds.), Cognition and education: The psychology of learning and motivation: Advances in research and theory, Vol. 55 (pp. 269-298). San Diego, CA: Academic Press.

Mestre, J. P., Ross, B. H., Brookes, D. T., Smith, A. D., \& Nokes, T. J. (2009). How cognitive science can promote conceptual understanding in physics classrooms. In I. M. Saleh \& M. S. Khine (Eds.), Fostering scientific habits of mind: Pedagogical knowledge and best practices in science education (pp. 3-8). Rotterdam, The Netherlands: Sense.

Mestre, J., Thaden-Koch, T., Dufresne, R., \& Gerace, W. (2004). The dependence of knowledge deployment on context among physics novices. In E. Redish \& M. Vicentini (Eds.), Proceedings of the International School of Physics "Enrico Fermi," Course CLVI, Research on physics education (pp. 367-408). Amsterdam, The Netherlands: IOS Press. 
Minstrell, J. (2001). Facets of students' thinking: Designing to cross the gap from research to standards-based practice. In K. Crowley, C. D. Schunn, \& T. Okada (Eds.), Designing for science: Implications for professional, instructional, and everyday science (pp. 415-444). Mahwah, NJ: Erlbaum.

Mitrovic, A. (2012). Fifteen years of constraint-based tutors: what we have achieved and where we are going. User Modeling and User-Adapted Interaction, 22, 39-72. doi:10.1007/s11257-011-9105-9

Newell, A. (1990). Unified theories of cognition. Cambridge, MA: Harvard University Press.

Nokes, T. J. (2009). Mechanisms of knowledge transfer. Thinking \& Reasoning, 15, 1-36. doi:10.1080/13546780802490186

Nokes, T. J., \& Ohlsson, S. (2005). Comparing multiple paths to mastery: What is learned? Cognitive Science, 29, 769-796. doi:10.1207/s15516709 $\operatorname{cog} 0000 \_32$

Ohlsson, S. (1992). Constraint-based student modeling. Journal of Artificial Intelligence and Education, 3, 429-447.

Ohlsson, S. (1993). The interaction between knowledge and practice in the acquisition of cognitive skills. In A. Meyrowitz \& S. Chipman (Eds.), Foundations of knowledge acquisition: Cognitive models of complex learning (pp. 147-208). Norwell, MA: Kluwer.

Ohlsson, S. (1996). Learning from performance errors. Psychological Review, 103, 241-262. doi:10.1037/0033-295X.103.2.241

Ohlsson, S., Ernst, A., \& Rees, E. (1992). The cognitive complexity of doing and learning arithmetic. Journal for Research in Mathematics Education, $23,441-467$.

Ohlsson, S., \& Mitrovic, A. (2006). Constraint-based knowledge representation for individualized instruction. Computer Science and Information Systems, 3, 1-22. doi:10.2298/CSIS0601001S

Ohlsson, S., \& Rees, E. (1991a). Adaptive search through constraint violations. Journal of Experimental and Theoretical Artificial Intelligence, 3, 33-42. doi:10.1080/09528139108915280

Ohlsson, S., \& Rees, E. (1991b). The function of conceptual understanding in the learning of arithmetic procedures. Cognition \& Instruction, 8 , 103-179. doi:10.1207/s1532690xci0802_1

Pennington, N., Nicolich, R., \& Rahm, J. (1995). Transfer of training between cognitive subskills: Is knowledge use specific? Cognitive Psychology, 28, 175-224. doi:10.1006/cogp.1995.1005

Pugh, K. J., \& Bergin, D. A. (2006). Motivational influences on transfer. Educational Psychologist, 41, 147-160. doi:10.1207/s15326985ep4103_2

Reed, S. K., Dempster, A., \& Ettinger, M. (1985). Usefulness of analogous solutions for solving algebra word problems. Journal of Experimental Psychology: Learning, Memory, and Cognition, 11, 106-125. doi:10.1037/0278-7393.11.1.106

Reeves, L. M., \& Weisberg, W. R. (1994). The role of content and abstract information in analogical transfer. Psychological Bulletin, 115, 381-400. doi:10.1037/0033-2909.115.3.381

Resnick, L. B., Michaels, S., \& O’Connor, C. (2010). How (well structured) talk builds the mind. In R. Sternberg \& D. Preiss (Eds.), From genes to context: New discoveries about learning from educational research and their applications (pp. 163-194). New York, NY: Springer.

Richland, L. E., Stigler, J. W., \& Holyoak, K. J. (2012). Teaching the conceptual structure of mathematics. Educational Psychologist, 47, 189-203. doi: $10.1080 / 00461520.2012 .667065$

Ross, B. H. (1984). Remindings and their effects in learning a cognitive skill. Cognitive Psychology, 16, 371-416. doi:10.1016/ 0010-0285(84)90014-8

Ross, B. H. (1987). This is like that: The use of earlier problems and the separation of similarity effects. Journal of Experimental Psychol- ogy: Learning, Memory, and Cognition, 13, 629-639. doi:10.1037/ 0278-7393.13.4.629

Salvucci, D. D., \& Anderson, J. R. (1994). Analogy. In J. R. Anderson \& C. Lebiere (Eds.), Atomic components of thought (pp. 343-383). Mahwah, NJ: Erlbaum.

Scherr, R. E., \& Hammer, D. (2009). Student behavior and epistemological framing: Examples from collaborative active-learning activities in physics. Cognition and Instruction, 27, 147-174. doi:10.1080/ 07370000902797379

Schunk, D. H. (2004). Learning theories: An educational perspective (4th ed.). Upper Saddle River, NJ: Pearson.

Schwartz, D. L., \& Bransford, J. D. (1998). A time for telling. Cognition and Instruction, 16, 475-522. doi:10.1207/s1532690xci1604_4

Schwartz, D. L., Bransford, J. D., \& Sears, D. (2005). Efficiency and innovation in transfer. In J. Mestre (Ed.), Transfer of learning from a modern multidisciplinary perspective (pp. 1-51). Greenwich, CT: Information Age.

Schwartz, D. L., \& Martin, T. (2004). Inventing to prepare for future learning: The hidden efficiency of encouraging original student production in statistics instruction. Cognition and Instruction, 22, 129-184. doi:10.1207/s1532690xci2202_1

Simon, H. A. (1956). Rational choice and the structure of the environment. Psychological Review, 63, 129-138. doi:10.1037/h0042769

Simon, H. A. (1993). Satisficing. In D. Greenwald (Ed.), The McGraw-Hill Encyclopedia of Economics (pp. 881-886). New York, NY: McGraw Hill.

Simon, H. A. (1996). The sciences of the artificial. Cambridge, MA: MIT Press.

Singley, M. K., \& Anderson, J. R. (1989). The transfer of cognitive skill. Cambridge, MA: Harvard University Press.

Taatgen, N.A. (2002). A model of individual differences in skill acquisition in the Kanfer-Ackerman air traffic control task. Cognitive Systems Research, 3, 103-112. doi:10.1016/S1389-0417(01)00049-3

Taatgen, N. A., \& Anderson, J. R. (2002). Why do children learn to say broke? A model of learning the past tense without feedback. Cognition, 86, 123-155. doi:10.1016/S0010-0277(02)00176-2

Taatgen, N. A., \& Lee, F. J. (2003). Production compilation: A simple mechanism to model complex skill acquisition. Human Factors, 45, 61-76. doi:10.1518/hfes.45.1.61.27224

Tannen, D. (1993). Framing in discourse. New York, NY: Oxford University Press.

Thaden-Koch, T., Dufresne, R. \& Mestre, J. (2006). Coordination of knowledge in judging animated motion. Physical Review E-Special Topics-Physics Education Research, 2, 020107.

Thorndike, E. L., \& Woodworth, R. S. (1901). The influence of improvement in one mental function upon the efficiency of other functions. Psychological Review, 8, 247-261. doi:10.1037/h0074898

Thorndyke, P. W. (1984). Applications of schema theory in cognitive research. In J. R. Anderson \& S. M. Kosslyn (Eds.), Tutorials in learning and memory: Essays in honor of Gordon Bower (pp. 167-192). New York, NY: Freeman.

Todd, P. M., \& Miller, G. F. (1999). From pride and prejudice to persuasion: Satisficing in mate search. In G. Gigerenzer, P. M. Todd, \& the ABC Research Group (Eds.), Simple heuristics that make us smart (pp. 287-308). New York, NY: Oxford University Press.

Urdan, T., \& Schoenfelder, E. (2006). Classroom effects on student motivation: Goal structures, social relationships, and competence beliefs. Journal of School Psychology, 44, 331-349. doi:10.1016/j.jsp.2006. 04.003 